\title{
Extensometer forensics: what can the data really tell us?
}

\author{
Thomas J. Burbey ${ }^{1}$
}

Received: 15 May 2019 / Accepted: 4 October 2019 /Published online: 7 December 2019

(C) The Author(s) 2019

\begin{abstract}
Extensometer data have an advantage over satellite-based data for monitoring land subsidence in that extensometer data provide continuous measurements (hourly or better temporal resolution) at very high precision (several tens of microns) over a known depth interval; the latter is important for isolating groundwater pumping from other causes of land subsidence attributed to tectonics or eustatic adjustments in the Earth's crust. This investigation aims to identify a semi-analytical procedure for quantifying aquifer and aquitard properties from a single extensometer record in lieu of the time-consuming development of more complex numerical models to quantify and constrain these parameter values. In spite of a limited 12-year record and the fact that water levels both decline and increase on an annual basis, this study successfully and reasonably estimated both aquifer and aquitard parameters at the Lorenzi extensometer site in Las Vegas Valley, Nevada (USA), when compared to the estimates developed numerically. The key factors that allow for estimates of elastic and inelastic skeletal-specific storage and hydraulic conductivity of the aquitards and elastic specific storage and hydraulic conductivity of the intervening aquifers is the presence of pumping cycles at multiple frequencies, and measured heads at all the aquifer units covered in the extensometer record. There is an inherent assumption that the aquitards possess the same hydrologic characteristics and are homogeneous and isotropic. This assumption is also a usual limitation in numerical modeling of these settings because of the complex temporal head relationships occurring within the aquitards that are rarely, if ever, measured.
\end{abstract}

Keywords Subsidence $\cdot$ Extensometers $\cdot$ Groundwater hydraulics $\cdot$ Groundwater monitoring

\section{Introduction}

The mechanisms causing land subsidence due to groundwater extraction are well established (Galloway and Burbey 2011; Poland 1967, 1972; Poland and Davis 1969) and the observation and measurement of land subsidence in many urban regions has been well documented both in the United States and abroad (Figueroa-Miranda et al. 2018; Galloway et al. 1999; Hsu et al. 2015; Tosi et al. 2016; Zhang et al. 2015; Zhu et al. 2015). Unfortunately, subsidence continues to be a problem in many areas worldwide (Castellazzi et al. 2016; Faunt et al. 2016; Hwang et al. 2016). In many cases the evidence of land subsidence can be observed directly by examination of damaged infrastructures and pipelines, differential settlement, earth fissures, distorted roadways, buckled sidewalks,

Thomas J. Burbey

tjburbey@vt.edu

1 Virginia Tech (Geosciences), 4044 Derring Hall, Blacksburg, VA 24061, USA nuisance flooding, protruding well casings, and other features. However, in many localities the extent and distribution of land subsidence was discovered from interferograms created from processing InSAR satellite data, which has become an extremely powerful tool for examining the spatial and temporal rates of surface deformation at the basin scale resulting from groundwater pumping where surface velocities tend to be large (on the order of centimeters per year; Galloway and Hoffman 2007; Hoffmann et al. 2001; Minderhoud et al. 2018). InSAR data have been successfully coupled with numerical models of flow and deformation to inversely quantify aquifer system properties such as the elastic and inelastic storage coefficients of the aquifer and aquitards (Hoffmann et al. 2003; Zhang and Burbey 2016), which has become one of the chief goals for measuring land subsidence.

Global positioning systems (GNSS or GPS) have also been widely used to provide point measurements of surface velocities associated with land subsidence from groundwater pumping (Abidin et al. 2008; Burbey et al. 2006; Carruth et al. 2007; Figueroa-Miranda et al. 2018). GPS or GNSS generally provide approximately the same level of vertical 
deformation precision as InSAR although differential GPS has shown to provide precision of a few millimeters in some cases (Abidin et al. 2008).

The advantage satellite-based methods for measuring land subsidence is that they are noninvasive, the data are inexpensive to obtain and process, and the results can provide details about the spatial heterogeneity of the aquifer system that cannot be obtained from limited point measurement data (Galloway and Hoffman 2007; Hoffmann et al. 2001). The disadvantage of areal satellite data (InSAR) is that they are not continuous. InSAR can typically only provide one measurement track per month (until the Sentinel-1 satellite was launched, which provides 12-day tracks over the United States) so cyclical pumping that is at a higher frequency cannot be coupled with InSAR data to characterize aquifer system properties. GNSS or GPS data are continuous and can represent a powerful way to confirm and couple InSAR-derived estimates of surface velocities and can allow for the interpolation of surface deformations between InSAR satellite passes. However, if cyclical pumping data are at a higher frequency than the measured deformation data, significant information about aquifer system response to pumping is potentially lost. As a whole, satellite-derived surface deformations and velocities incorporate all deformations including tectonic and eustatic changes that may be prevalent along coastlines attributed to sedimentation in delta environments and loading due to sea-level rise. Hence, if the goal is to investigate and determine deformation derived from groundwater pumping in coastal environments then extensometers may be required to differentiate between pumping induced subsidence and eustatic or tectonic forms of subsidence.

Extensometers have some distinct advantages over the aforementioned satellite-based methods. Firstly, if designed properly, they can accurately measure subsidence at the submillimeter or even to a few 10's of microns, which can be highly advantageous in settings where subsidence rates are not only very low, but also where evaluation of aquifer properties is nonetheless important. Secondly, the data are continuous so even if pumping occurs at diurnal frequencies, it is possible for the extensometer to record possible compaction from these high-frequency pumping events. Thirdly, in many localities there is a much longer historical record with extensometers than with satellite data. InSAR has only been available since the early 1990's and early GPS data were not nearly as accurate as today due to governmental selective availability (which was lifted in 2000) as GPS was developed for the US Army for national defense purposes. Extensometer data, on the other hand, have been available at some sites since the 1960 's, when subsidence rates were typically much higher due to the fact that subsidence was not as yet well known as a consequence to excessive groundwater pumping, therefore precluding subsidence mitigation strategies such as reduced use of groundwater or aquifer storage and recovery (ASR) operations. Fourthly, extensometers measure the compaction over the depth of the extensometer pipe, typically within the zone of active pumping (which is how they tend to be designed) so that tectonic and eustatic changes are not part of the deformation record. They are also not subject to topographic or elevation effects that often plague InSAR processing and can interfere with signal coherence. The two biggest disadvantages to the implementation of extensometers is the cost and the fact that they represent point measurements. As such, it is uncommon for more than a few extensometers to exist within an entire aquifer system or basin. Other, typically less troublesome, disadvantages include their need for regular maintenance, the influence of changing temperatures on the deformation record, and acquiring an optimal and available location for installation (it is often difficult to acquire a secure location in places most appropriate for monitoring the largest subsidence rates).

Extensometer data alone are limited to measuring the total land deformation from the base of the extensometer pipe to land surface, but at an extremely high precision and at time intervals of usually minutes to hours. However, and more importantly, when coupled with time-series water-level data in the aquifers through which the extensometer penetrates, the two data sets can yield important aquifer system hydrologic properties (Epstein 1987). Riley (1969) has shown that stressstrain diagrams obtained from the combined compaction and water-level cycles of pumping can yield reasonable estimates of the elastic and even inelastic skeletal-specific storage values of the aquifer system. In addition to the storage properties of the compacting system, Riley (1969) was able to estimate the time constant of the aquitards in question, which represents the time required to dissipate $93 \%$ of the excess pore pressure in the aquitards after an instantaneous increase in stress (Epstein 1987). The three key parameters in this calculation are the vertical hydraulic conductivity, which affects the length of time for the fluids to be expelled from the unit under a hydraulic gradient, the inelastic skeletal-specific storage, which affects the amount of compaction that will ultimately occur from the expulsion of fluids, and the thickness of the compacting aquitards. Zhuang et al. (2017) developed analytical procedures using cyclical pumping and flow relations in the aquitards to quantify the vertical hydraulic conductivity and elastic and inelastic specific storage of the aquitards in a two aquifer, single aquitard system. Further quantification of hydrologic parameters from extensometer and water-levels has been done through the far more sophisticated development of one- or two-dimensional (1D, 2D) numerical models that couple a compaction algorithm with fluid flow or pressure diffusion (Epstein 1987; Helm 1975, 1976; Pavelko 2004; Pope and Burbey 2004; Sneed and Galloway 2000).

The key factors that will ultimately determine the ability to quantify parameter values of the aquifer system as a whole, or 
for individual units, include the occurrence of cyclical pumping in which hydraulic heads recover from their maximum preconsolidation (past maximum) stress levels. Whether the long-term head values are declining or rising is also important because only in continued declining heads (maximum preconsolidation stresses are exceeded during successive pumping cycles) from the onset of pumping can one readily estimate the inelastic component of skeletal-specific storage using stress-strain analysis as outlined by Riley (1969). In addition, knowledge of the pumping rates responsible for the measured compaction and the distance to the pumping wells responsible for the head change and compaction is extremely important for obtaining important parameter values. Granted, pumping data responsible for compaction is not always readily available or easily evaluated, particularly in highly complex aquifer systems beneath cities that have numerous and spatially distributed pumping for municipal and domestic water needs. Riley did not use pumping data in his analysis of skeletal-specific storage, but the absence of such data limits the amount of information that can be obtained from the extensometer and water-level records.

The purpose of this forensic investigation is to closely examine extensometer and coupled water-level data of a multiple aquifer-aquitard system from a single site in Las Vegas Valley, Nevada (known as the Lorenzi site), by closely examining the period of data spanning 12 years from November 1995 to April 2007. By deconvolving the available years of water-level and compaction records into daily, seasonal, and decadal frequencies and analyzing the data at different time scales (frequencies), it will be shown that aquifer and aquitard parameters can be accurately quantified using historical knowledge of the system along with analytical and semianalytical methods that invoke new simplified approaches, without having to invoke the more highly involved and complex numerical modeling methods that have been previously undertaken to obtain parameter values. In this investigation for Las Vegas Valley, there are three aquitards separated by three aquifers. One advantage employed here is the knowledge of results of a 1D MODFLOW model using the SUB package to quantify system parameters for the Lorenzi site in Las Vegas (Pavelko 2004). These results are useful for assessing some of the results of the methodologies adapted in this investigation, assuming that the range of simulated results of Pavelko are reasonable and fairly accurate. Secondly, data analytics is used to process and mine these large data sets in ways that have not been previously adopted for extensometer data. The aim is to investigate whether simple analytical models can be used to quantify valuable hydrologic parameters of the multiple aquifer-aquitard system without having to develop far more complex numerical models. Additionally, because the Las Vegas data are highly complex and exhibit daily, seasonal, and decadal signals, and waterlevels trend from declining to rising during the period of record, it is important to understand too the limitations of what can and cannot be gleaned from these records based on the likely complex head distribution that occurs through the aquifer system under these circumstances as well as to understand what assumptions are necessary to be able to make reasonable parameter estimates.

\section{Field site and data}

Pumping has been occurring in Las Vegas Valley for nearly a century and subsequent land subsidence has been observed for more than 60 years when increased rates of groundwater withdrawal began to exceed natural recharge rates to the basin (Bell 1981; Harrill 1976; Malmberg 1964; Maxey and Jameson 1948; Maxey and Jameson 1964). The historical conditions for land subsidence to occur in the basin are highly favorable and include large water-level declines exceeding 90 m by 1990 (Burbey 1995) and thick compressible fine-grained aquitards or interbeds (Morgan and Dettinger 1996), occurring mainly in the western and northwestern parts of the basin, as total estimated land subsidence has measured $1.6 \mathrm{~m}$ (Bell et al. 2002) in the northwest subsidence bowl (Fig. 1) over the period from 1963-2000.

Harrill (1976), Bell (1981, 1991), and Morgan and Dettinger (1996) provide a detailed and thorough description of the geology and hydrogeology as well as an historical overview of land subsidence due to groundwater pumping in Las Vegas Valley. The interested reader is referred to these publications for a more detailed hydrogeological analysis of the Las Vegas basin. In brief, Las Vegas Valley represents an extensional structural basin filled with more than $1,500 \mathrm{~m}$ of alluvial deposits derived from the carbonate mountains to the west, siliciclastic deposits from the north and volcanic deposits from the east and south. Depositional sequences have produced a complex and heterogeneous sequence of aquifers and aquitards of varying thickness and compressibility. A near-surface aquifer overlies a more extensive principal aquifer system from which all domestic water originates in the valley. The principal aquifer contains various aquitards at the Lorenzi extensometer site (Fig. 1) but the near-surface aquifer is not identified at this locality and may be due to the abundance of caliche in the uppermost $22 \mathrm{~m}$ and fine-grained deposits (shallow aquitard), extending from land surface to a depth of about $78 \mathrm{~m}$. The principal aquifer system contains three aquitards and three aquifers, referred to here as the shallow, middle, and deep aquitards and aquifers, respectively. The naming convention developed by Pavelko (2000) is retained here for continuity. The aquifers are composed largely of sands and gravels with minor thin layers of silts and clays, while the aquitards are composed almost entirely of clays and silts. Drilling logs from the extensometer borehole (244-m total depth) and geophysical surveys have 


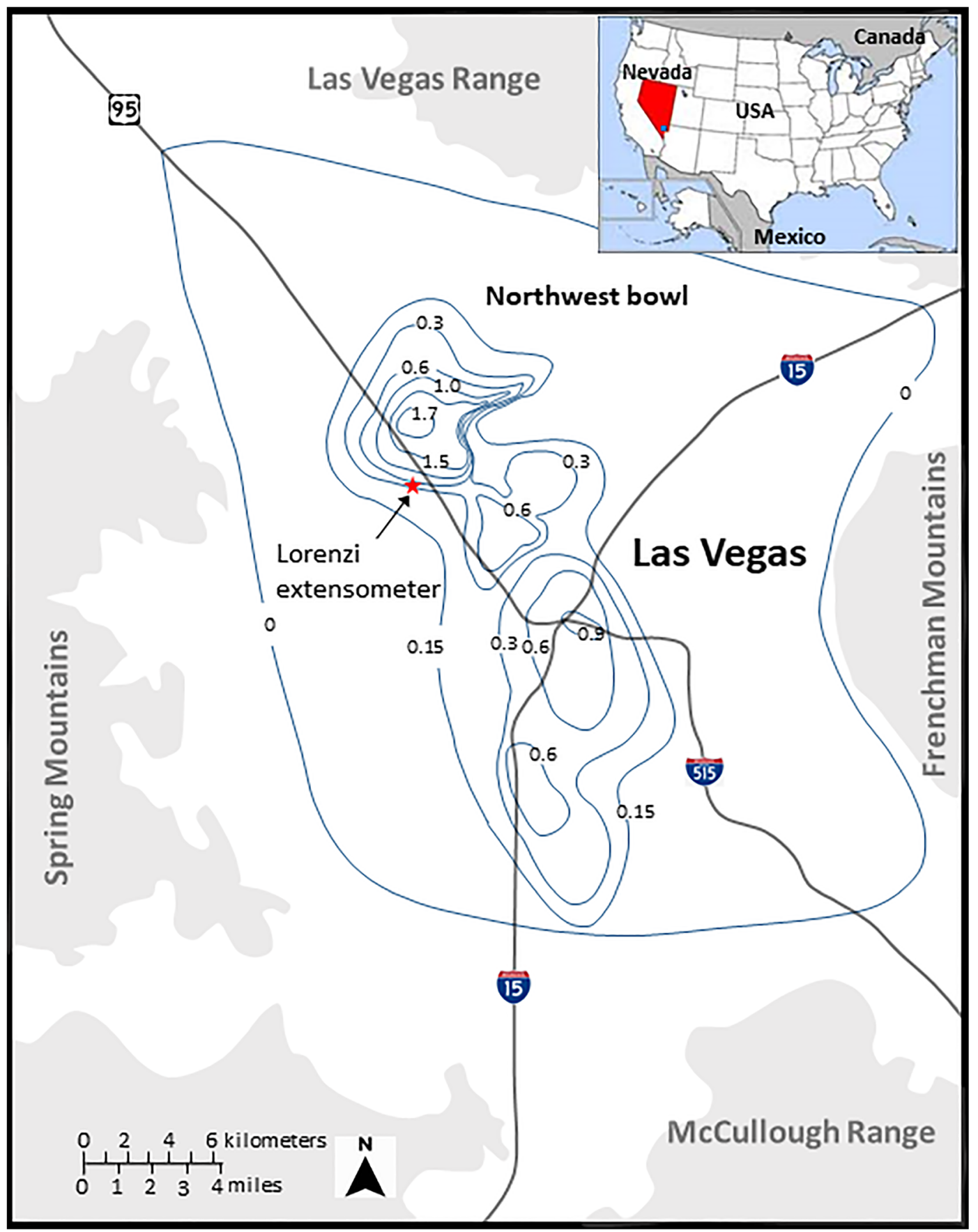

Fig. 1 Map of Las Vegas Valley showing the location of the Lorenzi extensometer site and estimated and measured land subsidence (blue contours, in meters) for the period 1963-1990, adapted from Bell et al. (2002). Black lines refer to major highways

defined the depths and thicknesses of the aquifer and aquitard units within the larger principal aquifer system of the basin (Pavelko 2000). Table 1 lists the depths and thicknesses of each of the aquifer and aquitard units, which will become important for the data analysis conducted in the forthcoming sections. A piezometer nest-2-inch $(0.051 \mathrm{~m}) \mathrm{PVC}$ with 10 $\mathrm{ft}(3.05 \mathrm{~m})$, screens - was installed to monitor water levels in each of the three aquifers.
A pipe extensometer extends through the deep aquifer into the underlying aquitard (not named) and is cemented at a depth of $244 \mathrm{~m}$ at the base of the deep aquifer. A series of three slip couplers were installed in the outer casing to reduce vertical stress while compaction occurs from increased effective stress due to pumping. A steel extensometer table sits over the extensometer pipe whose legs extend $4 \mathrm{~m}$ below land surface to minimize the recorded effects of shrink and swell 
Table 1 Depth intervals in meters below land surface (mbls) for the three aquifers and aquitards along with their overall thicknesses and screened piezometer zones. Units defined from drill cuttings and borehole geophysical logs (Pavelko 2000)

\begin{tabular}{llll}
\hline Unit & Interval (mbls) & Unit thickness (meters) & Screened interval (mbls) \\
\hline Shallow aquitard & $0-78$ & 78 & - \\
Shallow aquifer & $78-94$ & 16 & PZs (91.4-94.5) \\
Middle aquitard & $94-128$ & 34 & - \\
Middle aquifer & $128-152$ & 24 & PZm (136.3-139.4) \\
Deep aquitard & $152-184$ & 32 & - \\
Deep aquifer & $184-244$ & 60 & PZd (206.4-209.5) \\
\hline
\end{tabular}

of the soil column due to moisture and temperature fluctuations. A digital linear potentiometer connected to a data logger monitors the overall compaction at hourly intervals. A more thorough description of the extensometer installation setup is provided by Pavelko (2000). The extensometer is contained within a shed where temperatures were monitored continuously. The Lorenzi extensometer site is located within 3,000 m of about 14 municipal pumping wells that pump at different diurnal and seasonal rates. Figure 2 shows the entire available water level and subsidence record of the Lorenzi site from the US Geological Survey, extending from November 16, 1994 to December 5, 2007. Figure 3 more readily shows the daily water-level fluctuations that occur during the summer months (year 1998 is shown) when daily pumping rates vary to adjust to summertime daily demands.

Visual observation of the data (Fig. 2) reveals some very important aspects of the aquifer system. Clearly, the data show a consistent and periodic seasonal pattern of cyclical water levels and cumulative subsidence. This is consistent with the Las Vegas Valley Water District's annual pumping cycle, whereby summer pumping commences on or about April 1st and ends on or about October 1st of each year. The drop and rise in water levels appears to closely align with these dates, but closer inspection of the data are warranted to evaluate whether any hydrodynamic lag occurs between the waterlevel and compaction records. Another extremely important aspect of the data is the changes of yearly water levels from a decreasing annual trend to an increasing one in the latter years of the record. The first 3 years of the record (1995-1997) show declining water levels in spite of the fact that an artificial recharge program commenced in 1988 and significant quantities of water were injected into the principal aquifer beginning about 1990 during the winter months (Fig. 4). The lowest water levels in the record occurred at the end of the pumping season in 1997 (98.69 mbls); however, it is unlikely that this low head value represents a maximum preconsolidation stress since the decline in heads coincides with a decrease in artificial recharge. It is more likely that the lowest heads in the principal aquifer occurred prior to the commencement of artificial recharge in the valley (prior to 1988).

Water levels began to show recovery at the Lorenzi site in 1998 except for a brief decline in water levels in 2003 and
Fig. 2 Mean daily record of the subsidence and water level records for the shallow, middle and deep aquifers at the Lorenzi extensometer site for the entire measured record, 1995-2007

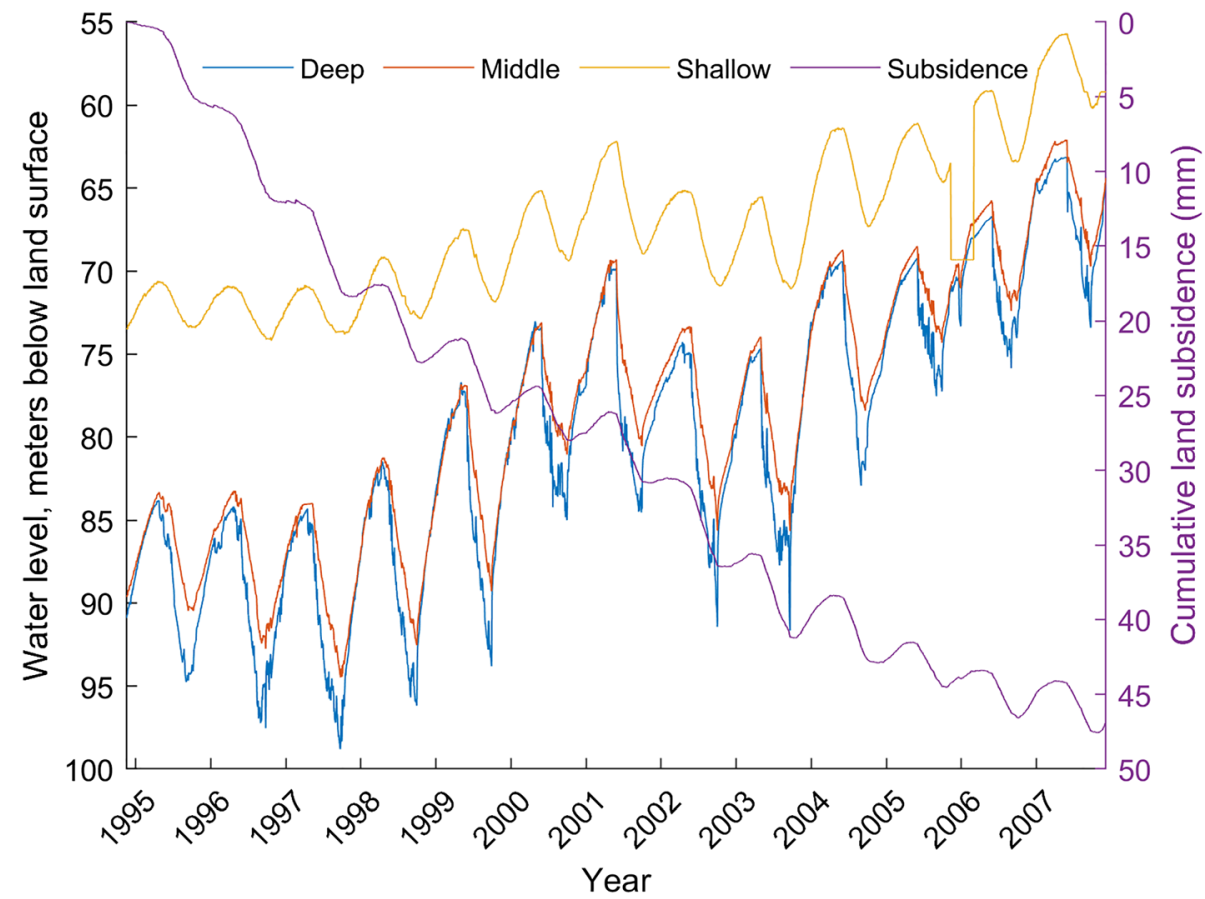


Fig. 3 Hourly subsidence and water-level record for a calendar year 1998 and b July 1998, measured at the Lorenzi extensometer site, showing the effects of diurnal variable pumping on the water-level record during the summer months (a)

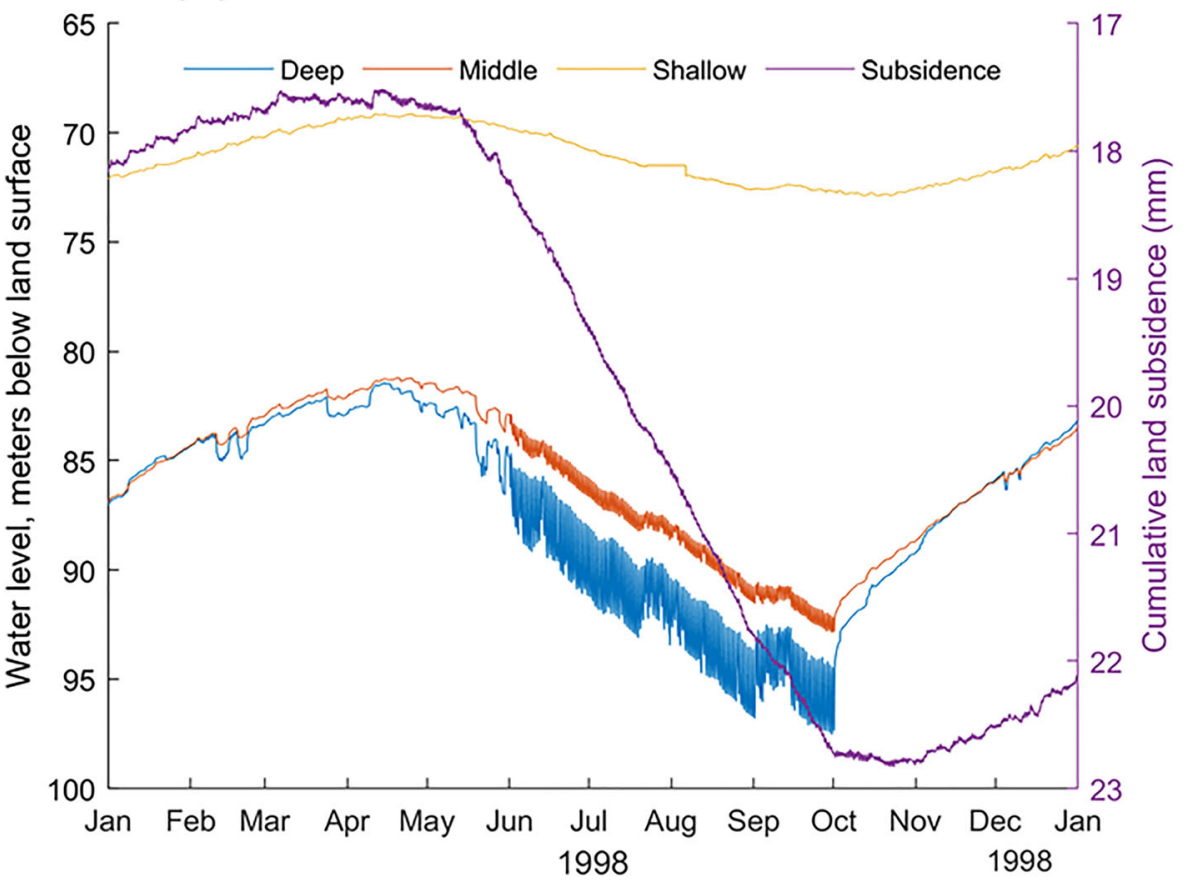

(b)

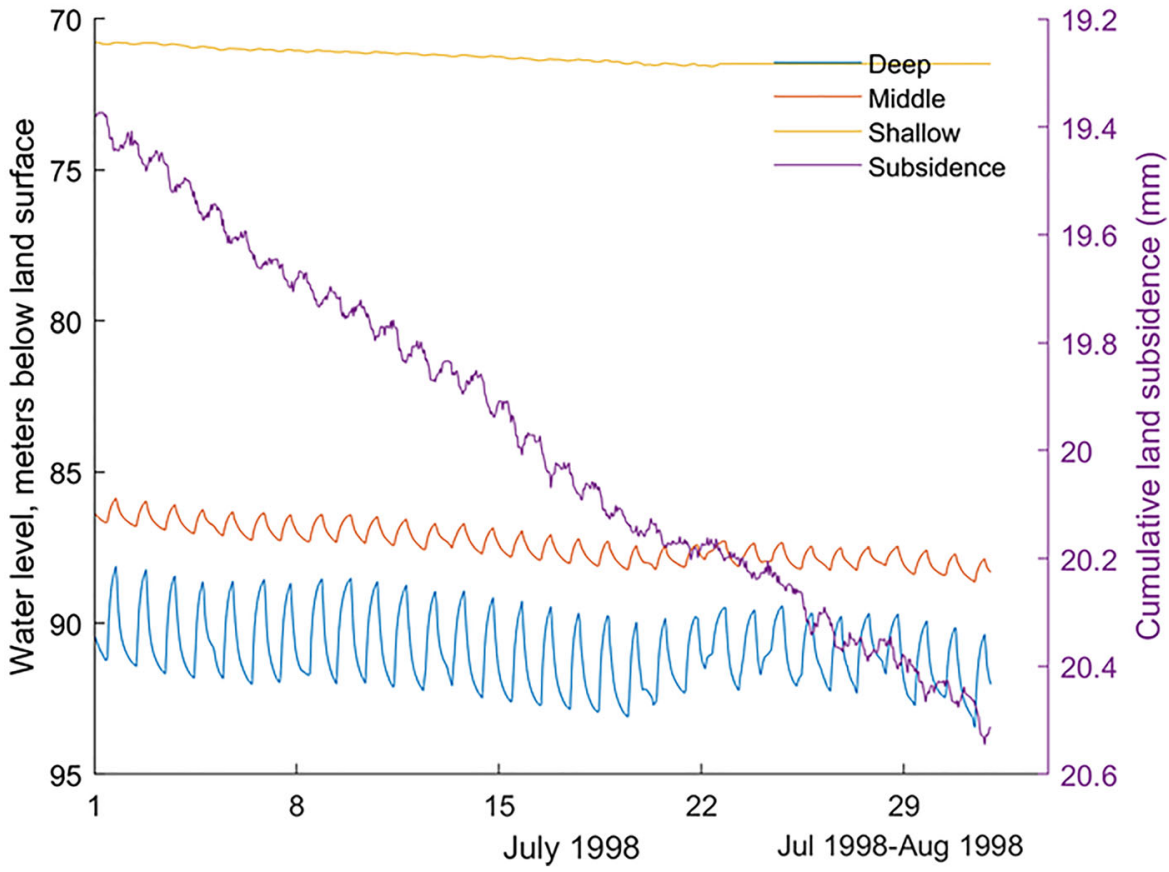

2004, which probably is associated with a sharp decline in the quantity of artificial recharge in 2002 (Fig. 4). Water levels again began to increase progressively until the end of the record in 2007. These increases are likely attributed to the increased rates of artificial recharge beginning in late 2003. During the water-level declines in 1995-1997, the compaction record shows continuous compaction even during the portion of the season when water levels recovered. However, when water levels began to recover in 1998, there is a notable winter elastic recovery in the compaction record superimposed on a continuous increase in long-term compaction. It is hypothesized that the seasonal elastic recovery is attributed almost entirely to the 


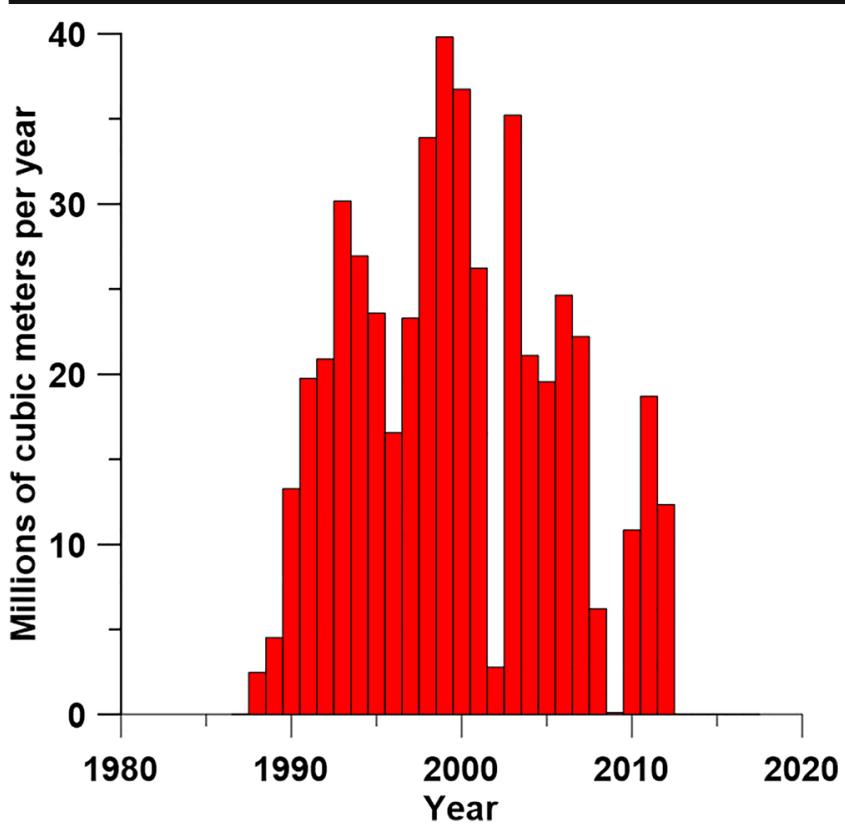

Fig. 4 Bar graph showing the annual quantity of injected artificial recharge to the principal aquifer system

elastic specific storage of the aquitards, while the continued annual increase in total compaction is attributed to the slow release of water from the aquitards that are not yet in equilibrium with the recovering heads in the aquifers. This annual (or more accurately decadal) compaction is associated with the inelastic specific storage of the aquitards. It should be noted too that the rate of long-term compaction decreases in response to the long-term water-level recovery and suggests that hydraulic gradients between the center of the aquitards and the adjacent aquifers have lowered, thus lowering the diffusive flux of water and subsequent rate of compaction. Furthermore, it is likely that the vertical hydraulic conductivity of the aquitards will decrease as compaction occurs over time.

Figure $3 \mathrm{a}, \mathrm{b}$ shows a higher frequency water-level and compaction record for 1998 and reveals that during the summer months a diurnal water-level fluctuation is evident in all three aquifers (although it is difficult to see these small fluctuations for the shallow aquifer at this scale) and is associated with a difference in night time versus daytime pumping of $5,400 \mathrm{~m}^{3} /$ $\mathrm{h}$. Because of the rapid decline and recovery of the aquifer heads, it is anticipated that the water-level response is entirely associated with the elastic storage of the aquifer units. The compaction response during these diurnal cycles is polluted with temperature effects that largely swamp out any possible compaction and recovery that may be occurring during these cycles. These temperature effects are associated with the thermal expansion and contraction in the steel in the upper portion of the extensometer pipe, the extensometer table, and the connections and housings supporting the linear potentiometer as daily temperature variations of $60^{\circ} \mathrm{F}$ commonly occurs in the summer months within the shed housing the extensometer (Pavelko 2000). The expansion- and contraction-induced temperature effect imposed on the extensometer record is approximately $0.07 \mathrm{~mm} /$ day but is easily identifiable because it responds contrarily to water-level changes. The temperature effect is considered negligible and does not affect the nature of the data at the seasonal and decadal time scales because daily mean data are used in these instances. Hourly subsidence data was not used in the analysis.

\section{Methods of data analysis}

The methodology steps are in part dependent on the nature of the head and subsidence data. In this analysis it is assumed that multiple periodic pumping frequencies occur over the course of the data set that allow for the distinction between aquifer and aquitard compressibilities. In such a case, the analysis steps are as follows:

1. Evaluation of aquifer elastic storage and horizontal hydraulic conductivity with the Theis equation using diurnal pumping signals that reflect the aquifer conditions only.

2. Evaluation of aquitard elastic skeletal storage and vertical hydraulic conductivity of the aquitards. The assumption here is that all the aquitards have the same hydraulic properties. The long-term inelastic signal is removed from the record. Seasonal periodic pumping is used as this length of pumping impacts a portion of the aquitards on a consistent yearly basis (elastic). An effective aquitard thickness undergoing elastic deformation is determined in this process.

3. Evaluation of aquitard inelastic storage is evaluated on the basis of known pumping history and the nature of the inelastic deformation time-series. In this approach a time-constant for the aquitards is approximated on the basis of aquitard thickness, the calculated hydraulic conductivity (from step 2) and the historical nature of the inelastic compression.

\section{Aquifer storage and hydraulic conductivity}

The first step in analyzing the aquifer system of the Lorenzi extensometer site is to attempt to quantify the aquifer properties. The fact that daily consistent periodic head fluctuations occur in the aquifers at the Lorenzi site during the summer months, attributed to differences in diurnal pumping rates, is highly advantageous for isolating the aquifer response apart from any leakage and subsequently compaction of the intervening aquitards. The rapid pumping and recovery response on a daily basis is too rapid for the aquitards to respond 
appropriately; hence, the water level cycles of Fig. 3a, b reflect an aquifer response to pumping.

For this analysis, a 5-day period in June 1998 (Fig. 5) is chosen where pumping and recovery periods are known as well as the pumping rates (Pavelko 2000). Under diurnal pumping cycles, the aquifers behave as confined units; therefore, to estimate the hydraulic conductivity and storage of the aquifers, the Theis equation is adapted to account for cycles of pumping and recovery over the three aquifers, from which the total diurnal change in pumping rate is $5,400 \mathrm{~m}^{3} / \mathrm{h}$ between the greater night and early morning pumping (Pavelko 2000) and the much lower daytime pumping. The head responses coincide perfectly with the pump off and on cycles.

The Jacob approximation to the Theis equation is valid for the diurnal pumping scenario at the Lorenzi extensometer site based on the amount of time elapsed (at least $8 \mathrm{~h}$ ) for each pumping sequence and can be written for cyclical pumping conditions as:

$s_{(k)}=\frac{Q_{(k)}}{4 \pi K_{(k)} b_{(k)}} \ln \left[\frac{2.25 K_{(k)} t}{r^{2} S_{\mathrm{s}(k)}}\right] \quad t \leq t_{1}$

$s_{(k)}=\frac{Q_{(k)}}{4 \pi K_{(k)} b_{(k)}} \ln \left[\frac{2.25 K_{(k)} t}{r^{2} S_{\mathrm{s}(k)}}\right]-\frac{Q_{(k)}}{4 \pi K_{(k)} b_{(k)}} \ln \left[\frac{2.25 K_{(k)}\left(t-t_{1}\right)}{r^{2} S_{\mathrm{s}(k)}}\right] \quad t>t_{1}$

where $s$ is the drawdown, $Q$ is the pumping rate and the index $(k)$ refers to the aquifer ( shallow $=1$, middle $=2$, or deep $=3$ ), $K$ is the hydraulic conductivity, $b$ is the aquifer thickness, $r$ is the distance from the pumping well to the observation wells, $S_{\mathrm{s}}$ is the specific storage (equal to storage coefficient $S$, divided by aquifer thickness $b$ ), $t$ is the total time (over all cycles of pumping) and $t_{1}$ is the time since pumping stopped. Pumping wells are located approximately 3,200 $\mathrm{m}$ south of the Lorenzi site. Pumping is typically apportioned to each aquifer from a modeling perspective as a weighting factor based on the relative transmissivity of each aquifer $(K \times b)$ compared to the total transmissivity of the sum of the aquifer transmissivities (Lieuallen-Dulam and Sawyer 1997). This would not be valid in this case, as it is assumed that the hydraulic conductivities of each aquifer are not substantially different, as the materials are comparable and a slight decrease in $K$ with depth is expected based on the increasing total load acting on the aquifer. However, the aquifer thickness increases with depth (Table 1); hence, the overall proportion based on transmissivity would likely yield nearly identical pumping rates for each aquifer. Clearly this is not the case based on the fact that the total head changes over a pumping cycle are very different in each aquifer. Not enough information is available to suggest that the pumping occurring equally from each aquifer and the heads would suggest that pumping is not apportioned equally. As such, pumping is apportioned to each aquifer based on the total relative head change over the range of the five cycles for the aquifer compared to the total head change across all three aquifers (expressed as a percentage). This approach yields the total pumping fractions of $0.02,0.21$ and 0.77 for the shallow, middle and deep aquifers, respectively. Table 2 (columns 3-5) shows the initial pumping rates for each aquifer based on these percentages.

Equation 1 shows that $K$ and $S_{\mathrm{s}}$ are unknown variables that need to be estimated. It is assumed that the aquitards are fixed laterally (based on available drilling logs) from the Lorenzi site to the source of pumping, which is averaged to be approximately 3,200 $\mathrm{m}$ toward the south. The radius to the pumping wells is approximate, but since $r$ is in the logarithm, changes in this parameter do not lead to significant changes in $s$ compared to $K$ and $S$. The shape and amplitude of the drawdown and recovery curves from cycles of pumping (selected for June 15-19, 1998) shown by the blue curves (observed heads) in Fig. 5 are diagnostic and dependent on the values of $K, S, Q$ and $r$. Estimates of $K$ and $S$ for each aquifer are evaluated by minimizing the objective function, $\Omega$, representing the sum of the squared residuals of drawdown (measured from a common starting head) using Eqs. (1) and (2) as

$\Omega(S, K)=\sum_{i=1}^{m}\left(s_{\mathrm{obs}}-S_{\mathrm{sim}}\right)^{2}$

where $s_{\text {obs }}$ are the observed heads measured at the shallow, middle or deep piezometers and $s_{\text {sim }}$ is the simulated drawdown obtained from Eqs. (1) and (2) for each aquifer. A MATLAB script was developed that applies Eq. (3) to each aquifer using the starting pumping distribution from Table 2. A range of reasonable skeletal storage coefficient $\left(S_{\mathrm{k}}\right)$ and $K$ values are used in the algorithm (Eqs. 1 and 2) and iterated until a minimization of Eq. (3) is achieved for each aquifer. Then, beginning with the deep aquifer, $Q$ is modified in $10 \%$ increments (both above and below values listed in Table 2) and the minimization process is conducted again. If the minimization for a refined pumping is lower than the previous objective function for a particular aquifer, that new pumping rate is used and the other pumping rates are modified to assure that the total pumping of $5,400 \mathrm{~m}^{3} / \mathrm{h}$ is maintained. The orange curves in Fig. 5 are the best-fit simulated drawdowns for each aquifer using this minimization process. Table 2 shows the final pumping distribution and simulated (horizontal) hydraulic conductivity, $K$, storage coefficient, $S$, and specific storage, $S_{\mathrm{s}}$, for each aquifer. The calibrated parameters not only closely approximate those of Pavelko (2004) from his calibrated 1D numerical model, the values fall within the range of values for Las Vegas Valley as estimated by Morgan and Dettinger (1996).

\section{Aquitard elastic storage and hydraulic conductivity}

The next goal is to determine if the aquitard parameters can be evaluated from the complex extensometer and piezometer records (Fig. 2). Because no water-level data are available 
Fig. 5 Measured (orange) and calibrated (blue) water levels at the nested piezometers of the Lorenzi extensometer site using the Theis equation during a 5-day period in July 1998

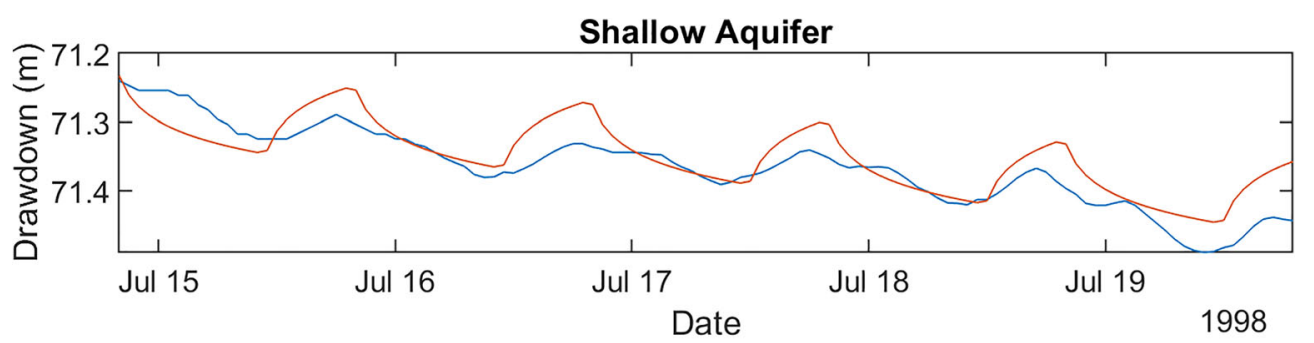

Middle Aquifer

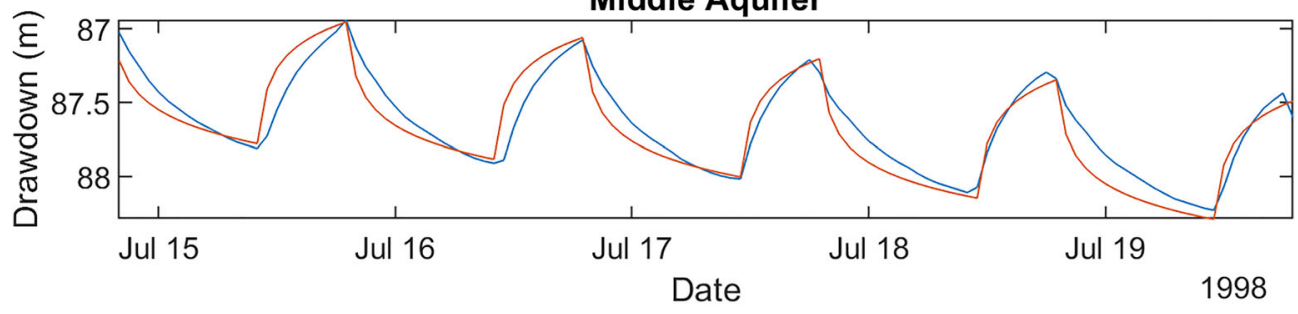

Deep Aquifer

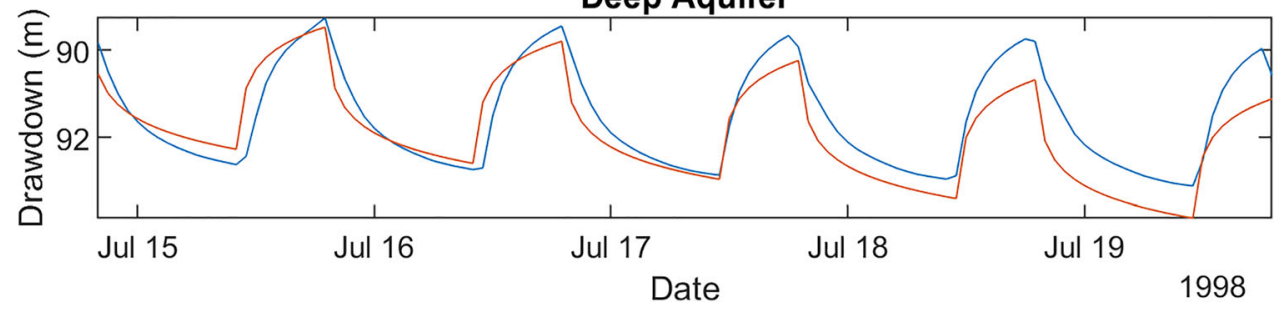

from within any of the aquitards and because only one composite compaction record is available, it must be assumed that each of the three aquitards exhibit the same behavior and thus have the same parameter values of vertical hydraulic conductivity (the direction of water movement out of the aquitards) and elastic and inelastic storage. This generalization is not particularly restrictive since even the more sophisticated 1D numerical MODFLOW model conducted for the site by Pavelko (2004) assumed constant aquifer and aquitard parameters. Without detailed head distributions within each of the aquitards, it is not possible to make a distinction between the aquitards with only a single cumulative extensometer record.

As indicated, regarding the seasonal response of the compaction record in Fig. 2, it is hypothesized that the seasonal elastic response of the total subsidence is attributed to the aquitards and is associated with the seasonal head changes in the aquifers. In general, a hydrodynamic lag will exist between the measured heads and the compaction occurring within the lower permeable aquitards (Zhuang et al. 2017). However, for longer (seasonal cycles) of head, an elastic lagfree response can occur within the aquitards. This lag-free response is dependent on the hydraulic diffusivity of the aquitard and its thickness undergoing elastic deformation, which is also dependent on the length of the head cycle. To validate this hypothesis, verification is needed to assure that the seasonal responses are fully elastic and that no hydrodynamic lag exists in the record, which would indicate that an inelastic component of storage exists in the seasonal record.
An auto-spectral analysis was performed on the deep waterlevel and subsidence records (the record with the largest amplitude of head seasonal head change), which describes the distribution of variance contained in the signal as a function of wavelength. An unbiased estimator of the autocovariance, $\operatorname{cov}_{x x}$, of the signal $x(t)$, which can represent water levels or subsidence in this investigation, with $N$ data points over a constant hourly time interval is

$\operatorname{cov}_{x x}=\frac{1}{N-j-1} \sum_{t=1}^{N-j}\left(x_{i}-\bar{x}\right)\left(x_{i+j}-\bar{x}\right)$

where $\bar{x}$ is the mean and $j$ is the time lag. An autocorrelation is calculated from Eq. (4) and then the power spectra is calculated using the Blackman and Tukey (1958) method. Figure 6a,b shows the auto-spectra results for both the deep water levels and subsidence records. Clearly, the power spectra reveal a single peak at a frequency of $0.00274 /$ day, which is equivalent to precisely 1 year for the entire period of record. The crossspectrum correlates the two time-series (Fig. 6a,b) in the frequency domain and the equation is similar to Eq. (4) and is written as follows:

$\operatorname{cov}_{x y}=\frac{1}{N-j-1} \sum_{t=1}^{N-j}\left(x_{i}-\bar{x}\right)\left(y_{i+j}-\bar{y}\right)$

where $x$ represents the water-level data and $y$ the subsidence data. A cross-correlation is calculated from Eq. (4) and the Blackman and Tukey (1958) method is used as before to 
Table 2 Calibrated hydraulic conductivity and storage parameters for the shallow, middle and deep aquifers using the Theis equation for cyclical daily pumping

\begin{tabular}{llllllll}
\hline Aquifer & Piezometer & $\begin{array}{l}\text { Initial percent of total } \\
\text { pumping }\end{array}$ & $\begin{array}{l}\text { Initial pumping rate } \\
\left(\mathrm{m}^{3} / \mathrm{h}\right)\end{array}$ & $\begin{array}{l}\text { Final calibrated pumping rate } \\
\left(\mathrm{m}^{3} / \mathrm{h}\right)\end{array}$ & $\begin{array}{l}\text { Calibrated } K \\
(\mathrm{~m} / \mathrm{s})\end{array}$ & $\begin{array}{l}\text { Calibrated } \\
S_{\mathrm{k}}(1 / \mathrm{m})\end{array}$ & $\begin{array}{l}S_{\text {sk }}(1 / \mathrm{m}) \\
\text { Shallow }\end{array}$ \\
Middle & PZm & 2 & 108 & 150 & 0.0065 & $4 \times 10^{-5}$ & $2.5 \times 10^{-6}$ \\
Deep & PZd & 77 & 1134 & 1100 & 0.0045 & $1.6 \times 10^{-5}$ & $6.6 \times 10^{-7}$ \\
\hline
\end{tabular}

calculate the cross spectrum. The results (Fig. 6c) clearly show a near perfect correlation at the same frequency (no lag) and indicates a perfectly elastic response between the heads and compaction at the seasonal (yearly) scale for the entire 12-year record.

To isolate the seasonal elastic response of the system a lowpass filter is used to remove the long-term decadal trend (inelastic component) of system compaction (Fig. 7) and then to fit a periodic sine function to the seasonal elastic response. The mean seasonal elastic recovery can then be readily calculated from the mean fitted periodic curve and is $2.7 \mathrm{~mm}$. Next, identifying the seasonal subsidence contribution of each aquifer from the total seasonal compaction record is accomplished through the following equation:

$\sum_{i=1}^{n} \Delta b_{i}=\sum_{i=1}^{n} S_{i} \Delta h_{i}$

where $\Delta b$ is the compaction in aquifer $i(i=1-3, n=3), S$ is the storage coefficient for the aquifer evaluated from the Theis equation (Table 2), and $\Delta h$ is the seasonal head change shown for each aquifer (i). By deconvolving the total head record for each aquifer and isolating the seasonal head change using a low-pass filter, the longer decadal trend is removed from the record. The head change is then fitted to a mean sine function, which represents the mean seasonal head amplitude over the period of record as shown in Figs. 8, 9 and 10 for each of the three aquifers. The middle plot (labeled b) of these figures leaves only the seasonal changes for each year, while the lower plot shows the sine function fit and represents the frequency and mean amplitude for the entire period of record. From this analysis, the total seasonal head change for the shallow, middle, and deep aquifers is $4.7,8.04$ and $10.23 \mathrm{~m}$, respectively. Multiplying these head changes by the aquifer storage coefficient according to Eq. (6), yields aquifer compactions for the shallow, middle, and deep aquifers of $0.19,0.13$ and $0.13 \mathrm{~mm}$, respectively. The sum produces a cumulative compaction assigned to the three aquifers of $0.45 \mathrm{~mm}$. This outcome reveals that $26 \%$ of the total seasonal compaction is attributed to the aquifers; therefore, the remaining $74 \%$ of the seasonal compaction, or $2.25 \mathrm{~mm}$, must be coming from the three aquitards. Under the assumption of a homogeneous, isotropic aquitards (equal elastic storage coefficient for all units), the head decline in each aquifer during each pumping cycle would drive the elastic compaction occurring from the same (as yet unknown) thickness of the aquitards both above and below the shallow and middle aquifers and from only above the deep aquifer. Using the relative head changes results in 12, 35 and $53 \%$ of the total compaction originating from the shallow, middle and deep aquitards, respectively. This translates to a total compaction assigned to each of the three aquitards as $0.27,0.79$, and $1.19 \mathrm{~mm}$, respectively.

Riley (1969) formulated an expression for the time constant, $\tau$, for homogeneous aquitards that describes the time required to attain any specified dissipation of average pore pressure from within the unit. The time constant, according to Riley, is a measure of the volume of water that must be squeezed out of the aquitards as a result of the increased stress (loss in pore pressure) and the impedance of the water from the unit (vertical hydraulic conductivity). For a singly draining unit (aquifer head decline causes an elastic response to one side of the aquitard) the time constant is defined as:

$\tau=\frac{S_{\mathrm{sk}}^{\prime}\left(b^{\prime}\right)^{2}}{K_{\mathrm{v}}^{\prime}}$

where the primes indicate the variables pertaining to the aquitard and $b^{\prime}$ is the length of the drainage path, $K_{\mathrm{v}}^{\prime}$ is the vertical hydraulic conductivity of the aquitard and $S_{\mathrm{sk}}^{\prime}$ is the aquitard skeletal-specific storage. Because the compressibility of the aquitard units is generally three or more orders of magnitude greater than water compressibility, the contribution of water expansion due to a decrease in pore pressure is generally ignored in these environments. Hence, the use of skeletalspecific storage as opposed to the total specific storage that generally includes the contribution of water compressibility (expansion).

The time constant (Eq. 7) represents the time required to dissipate $93 \%$ of the excess pore pressure in the aquitards after an instantaneous increase in applied stress (reduction in hydraulic head). It is not uncommon for the time constant to reach 10's to 1,000's of years for thick highly compressible clay beds that have low hydraulic conductivity. However, in this analysis a reverse approach is used where it is assumed that the time constant is equal to the seasonal pumping period of 182 days, which effectually produces the effective thickness of the 
Fig. 6 Auto spectral and cross spectral analyses of deep water level and subsidence for the entire period of record at the Lorenzi extensometer site revealing no lag between water levels and subsidence from yearly cyclical pumping

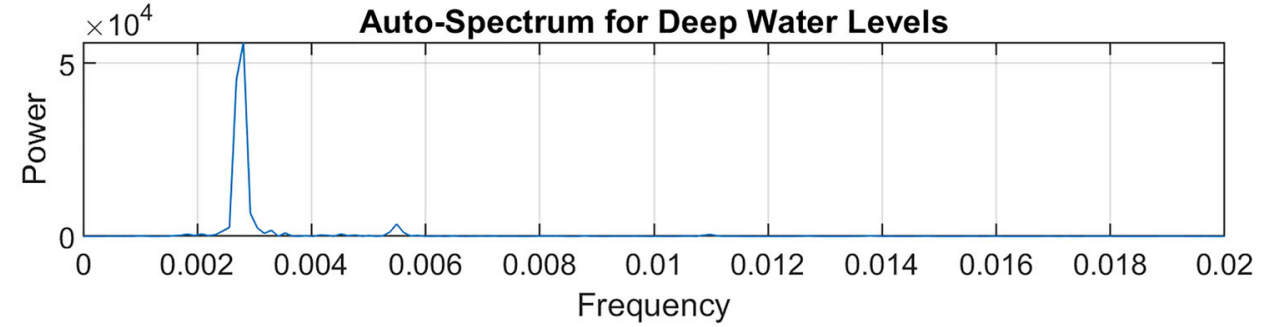

Auto-Spectrum for Subsidence

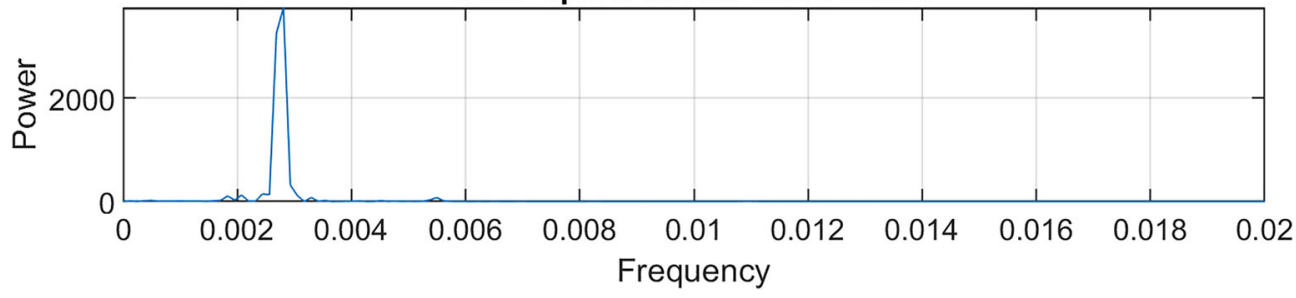

Cross-Spectrum

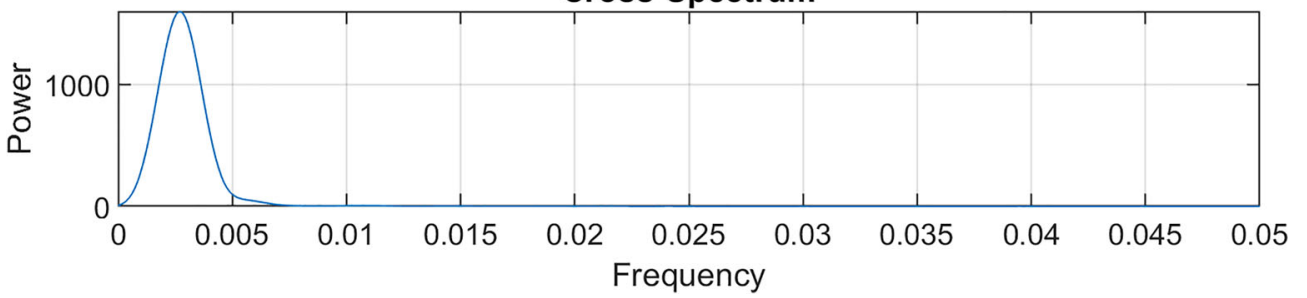

aquitards that undergo elastic deformation. It is known that, during this time period, the aquitards act elastically so the specific storage will represent the elastic component $\left(S_{\text {ske }}^{\prime}\right)$. Under these conditions $b^{\prime}$ refers to the thickness of the aquitard undergoing elastic deformation during the time of pumping. This thickness is independent of the magnitude of head change occurring within the unit. Figure 11 shows a plot of different elastic-aquitard thicknesses for different values of elastic skeletal-specific storage and vertical aquitards hydraulic conductivity. The shaded box shows the range of values obtained from the literature from eight different sites across the country where extensometer data were used to obtain aquitard parameter values either graphically (stress-strain diagrams), or numerically (1D or 2D flow and compaction models) - Epstein 1987; Hanson 1989; Heywood 2003; Pavelko 2004; Pope and Burbey 2004; Riley 1969; Sneed and Galloway 2000). The point within the box is the numerically calibrated values of these aquitard parameters from Pavelko (2004) for the Lorenzi site in Las Vegas. Based on these data, the mean elastic aquitard thickness undergoing seasonal response varies from 3$5 \mathrm{~m}$ with $4 \mathrm{~m}$ being the average and optimal value used in this analysis with 3 and $5 \mathrm{~m}$ representing the upper and lower range of reasonable thicknesses, respectively. This thickness represents the vertical extent into the aquitards directly adjacent to the aquifers that respond elastically to the seasonal head changes in the adjacent aquifers.

The skeletal elastic storage coefficient can now be estimated through the equation
$S_{\mathrm{ke}}^{\prime}=\frac{\Delta b^{\prime}}{\Delta h}$

Since it is assumed that homogeneous conditions exist for the aquitards only a mean value for Eq. (8) can be realistically applied. Furthermore, since it is known that the thickness of the compacting aquitard to be 8,8 , and $4 \mathrm{~m}$, respectively, surrounding the shallow, middle and deep aquifers, the elastic skeletalspecific storage can also be readily calculated and the mean value is provided in Table 3 along with the upper and lower ranges. The mean optimal skeletal storage and skeletal-specific storage values are calculated to be $S_{\mathrm{ke}}^{\prime}=1.15 \times 10^{-4}$ and $S_{\text {ske }}^{\prime}$ $=1.6 \times 10^{-5} / \mathrm{m}$, respectively. Finally, using Eq. (7) to solve for the aquitard's hydraulic conductivity (all the other parameters are now evaluated) yields an estimate of $K_{\mathrm{v}}^{\prime}=1.4 \times 10^{-6} \mathrm{~m} /$ day. A range is also provided in Table 3 based on the range of $b^{\prime}$ values used in Eq. (8) and the range of $S_{\text {ske }}^{\prime}$ values shown in Table 3. It should be noted that since the aquitards are homogeneous, this value of hydraulic conductivity is valid for deformation in the inelastic range as well.

\section{Aquitard inelastic storage}

Obtaining an accurate estimate of the inelastic specific storage of the aquitards is a far more daunting task. The key reason for this difficulty is that the heads in the aquitards are not in equilibrium with the measured heads in the 
Fig. 7 a Long-term subsidence (blue) with trend line (orange), b long-term subsidence trend removed to reveal annual subsidence pattern over period of record, and $\mathbf{c}$ annual subsidence (blue) with sine wave fit (orange) showing mean frequency and amplitude of annual elastic subsidence due to persistent seasonal pumping patterns
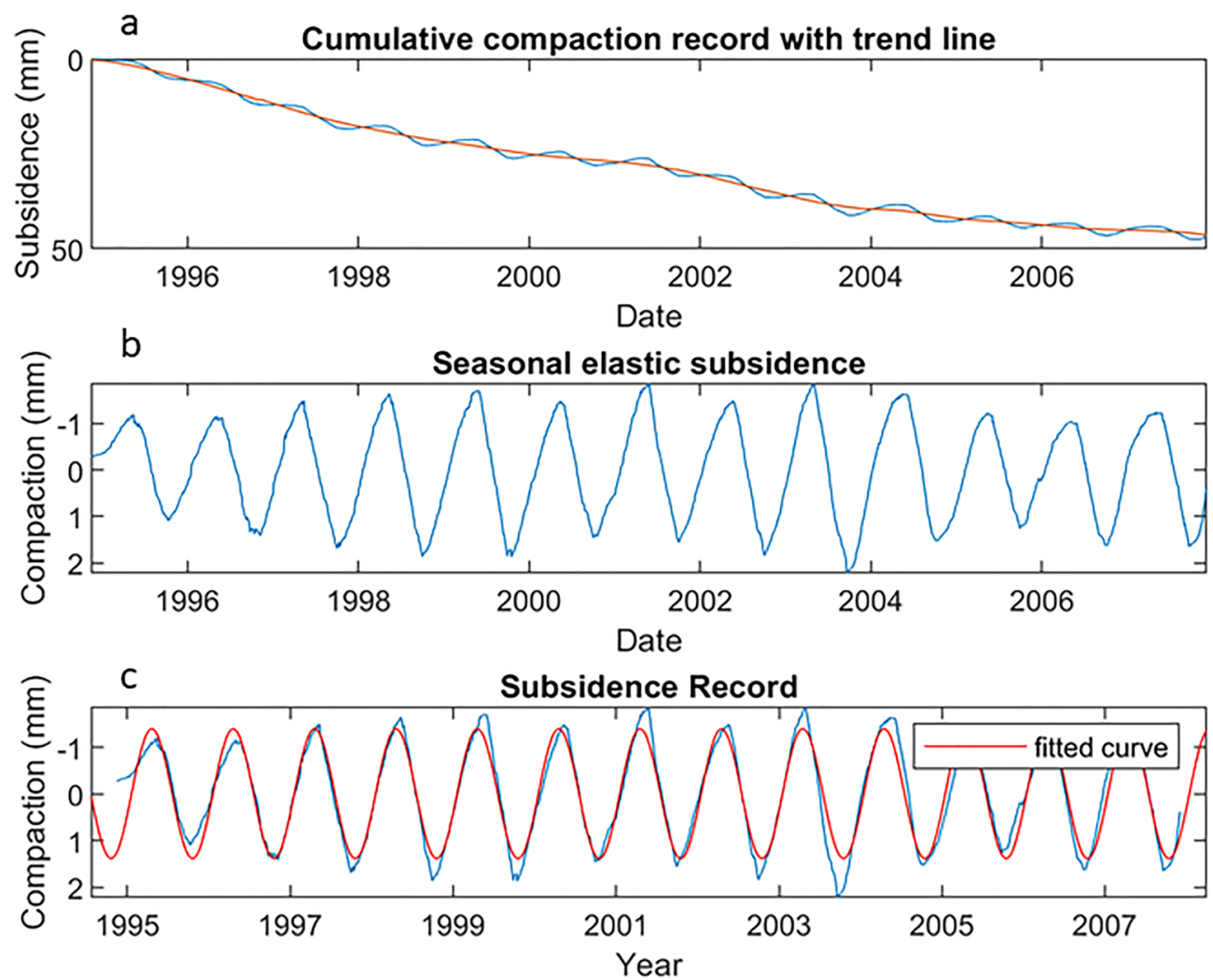

aquifers due to the slow release of water from these units, creating a hydrodynamic lag between the heads in the aquifer and the observed subsidence. This is clearly evident in the long-term compaction record shown in Fig. 2 where the mean annual water levels show a recovery for the last 4 years of record, yet a net decline in the land surface elevation is still occurring, which indicates that the heads within the aquitard are not in equilibrium with the heads in the aquifer. In the 1D MODFLOW numerical model developed by Pavelko (2004), where he implemented the SUB package to simulate delayed drainage of the aquitards, the simulated head distribution within the aquitards at various times is shown in Fig. 12 to highlight the complex nature of the heads over time. In particular, because the heads in the first few years of the data set are decreasing and the heads in later years are recovering, the resulting heads in the aquitards show a continual decline at their centers (expulsion of water), but show both declining and increasing heads in the portion of the aquitards nearest the aquifers (the elastic aquitard response). This creates a highly complex head distribution over time (Fig. 12).

Riley (1969) developed a methodology for estimating the inelastic skeletal-specific storage from stress-strain distributions for an aquifer system near Pixley, California (USA). In this methodology the seasonal changes in pumping created annual hysteresis loops (elastic recovery), but the continued pumping led to an annual increase in preconsolidation stress (continuous annual hydraulic head decline) that allowed for the tops of each annual loop to be connected over many years to produce a linear trend whose slope reflects the inelastic specific storage of the aquifer. The key condition in this approach is that the mean annual heads continue to decline. This is not the case at the Lorenzi site in Las Vegas (Fig. 2) and therefore this approach is not feasible in spite of the fact that compaction continues throughout the period of record. However, the long-term trend (annual to decadal compaction) in subsidence shows a significant change in slope that is associated with the slowing of drainage from the aquitards as the heads in the aquifers begin to recover. A linear annual trend can be found when plotting heads against compaction data with a high degree of correlation; however, the slope associated with such a trend does not reflect the inelastic specific storage of the aquitards.

In this analysis, a more semi-analytical approach is used. Since it is likely that compaction has been ongoing (no uplift) at this site since the inception of pumping in Las Vegas Valley, the time constant is set to be equal to the total time of pumping (and commencement of head declines), which is roughly 90 years. This value is reasonable for the thicknesses of the middle and lower aquitards based on estimates from this and other systems (Epstein 1987; Pavelko 2004; Sneed and Galloway 2000). Using again Riley's (1969) expression for the time constant for doubly draining aquitards and rearranging to solve for the specific storage, which in this case now 
Fig. 8 a Long-term shallow piezometer record (blue) with trend line (orange), b seasonal water levels with trend removed and $\mathbf{c}$ seasonal water levels (blue) with fitted sine function (orange) revealing mean frequency and amplitude of water levels in the shallow aquifer. The step near year 2006 reveals missing data
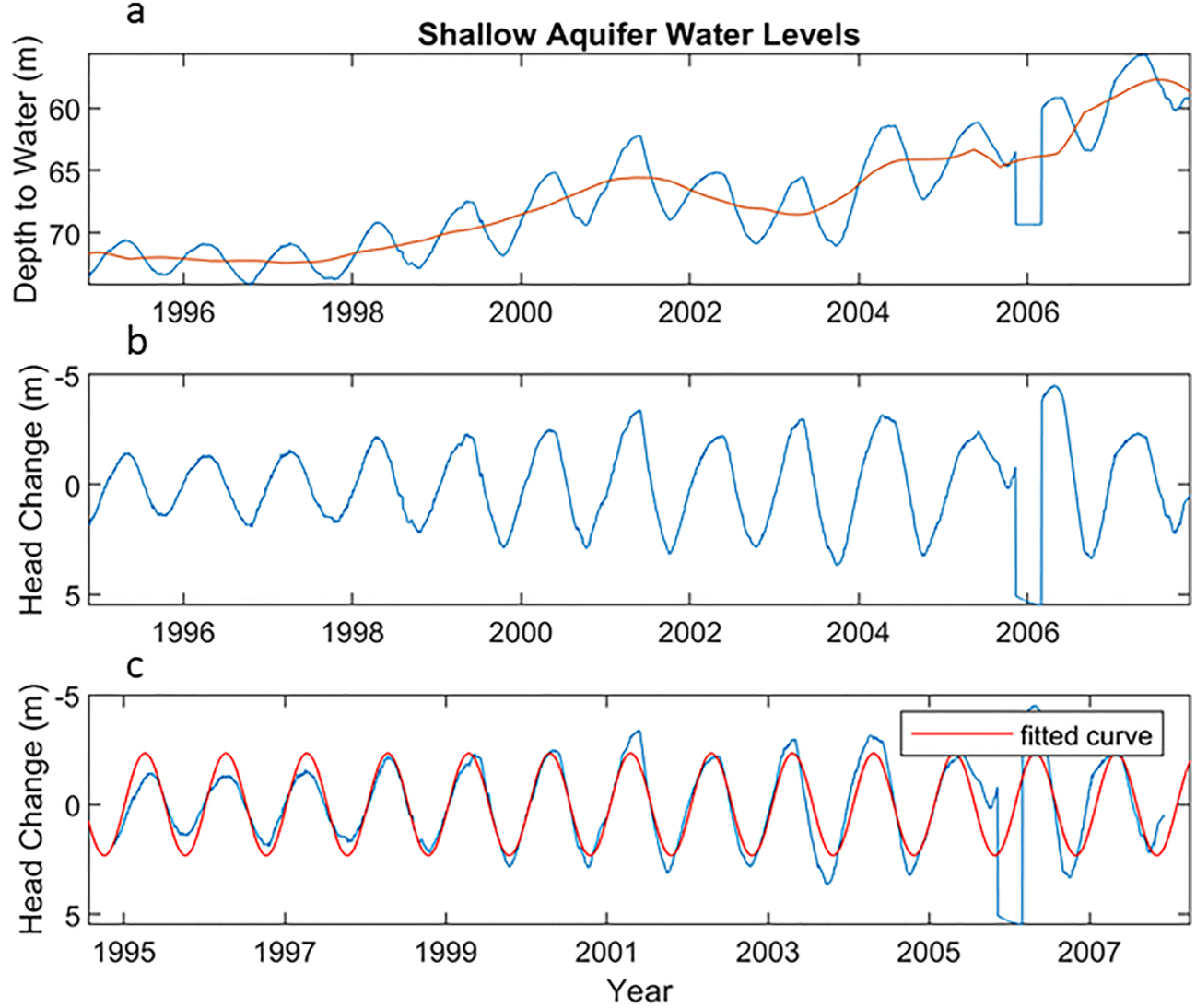

refers to the inelastic skeletal-specific storage of the aquitards

$S_{\mathrm{skv}}^{\prime}=\frac{\tau K_{\mathrm{v}}^{\prime}}{\left(b^{\prime} / 2\right)^{2}}$

The thickness of each of the lower two aquitards is nearly identical (Table 1) so an average thickness of $33 \mathrm{~m}$ is used here. The vertical hydraulic conductivity was calculated previously from the analysis of the elastic properties of the aquitards (Table 3). Figure 13 shows the different possible time constants for the average aquitard thickness of $33 \mathrm{~m}$ for a range of hydraulic conductivity and inelastic skeletal-specific storage values of the aquitards. The orange-shaded zone represents a reasonable range of inelastic skeletal-specific storage based on previous extensometer investigations (usually determined numerically) and the hydraulic conductivity calculated here. The red circle represents the calibrated value of Pavelko (2004) from his 1D numerical model. Using 90 years as the time constant represents the minimum realistic time constant since compaction is still occurring in the inelastic range from the inception of pumping (Fig. 7a). Furthermore, since the water-level recoveries are clearly impacting the slope of the long-term compaction record, it is unlikely the time constant for these aquitards is likely to exceed 200 years. Figure 7 a shows that the compaction is asymptotically approaching zero temporal change, which implies that the dispersive flux from the aquitards is decreasing at the same rate as the rate of compaction (assuming constant parameter values for $S_{\text {skv }}^{\prime}$ and $K_{\mathrm{v}}^{\prime}$ ). This result at least qualitatively implies that the aquitards are approaching equilibrium with the heads in the aquifers. Even with a 110-year possible range for the time constant, this greatly narrows the possible range of viable $S_{\mathrm{skv}}^{\prime}$ values to a factor of only 2 (Fig. 13; Table 3). The 90-year time constant yields a calculation of $S_{\text {skv }}^{\prime}=1.7 \times 10^{-4} / \mathrm{m}$, which is nearly identical to the value produced numerically by Pavelko (2004). Pavelko calculated a time constant of 100 years based on Eq. (7) by numerically calibrating the aquitard parameters.

One could argue that this simplistic way for estimating $\tau$ is not valid or even reasonable, particularly in basins that have perhaps just recently been undergoing pumping and head declines. This indeed is true for basins where compaction rates are large and head declines continue to annually exceed their past maximum preconsolidation stress values, but then the stress-strain method of Riley (1969) would likely be a more fitting approach under these circumstance while representing a more rigorous analytical methodology for estimating the inelastic skeletal-specific storage. Clearly, this semi-analytical approach toward assigning a value to the time constant is reasonable for basins that have undergone decades of pumping and water-level decline, where knowledge of the 
Fig. 9 a Long-term middle piezometer record (blue) with trend line (orange), b seasonal water levels with trend removed and $\mathbf{c}$ seasonal water levels (blue) with fitted sine function (orange) revealing mean frequency and amplitude of water levels in the middle aquifer
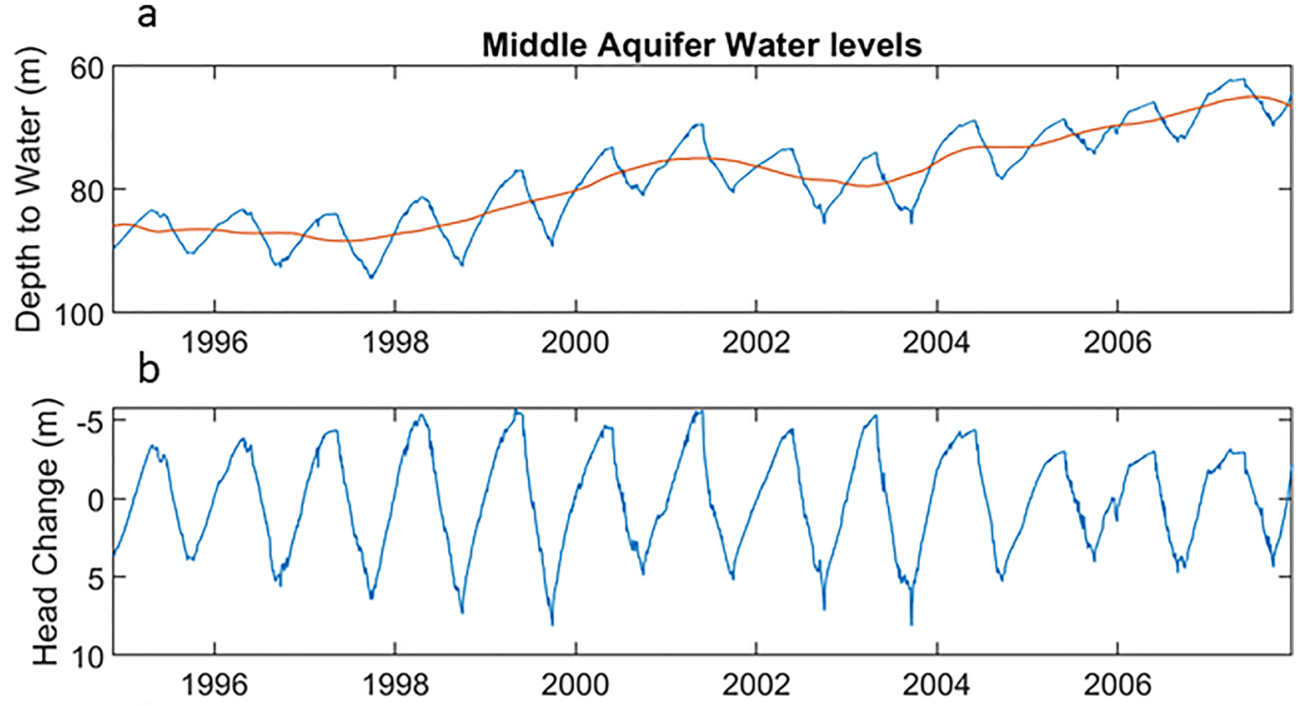

C

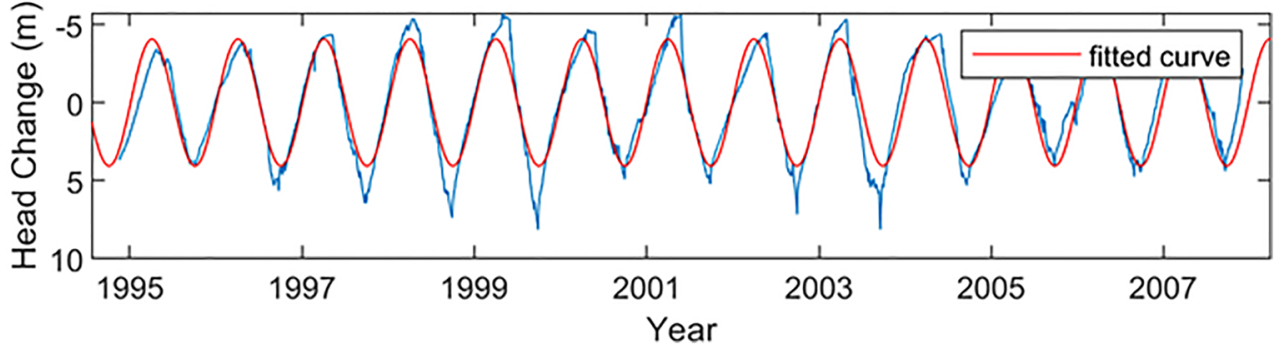

aquitard thickness is known and where the annual rate of compaction is asymptotically approaching zero, which indicates that the system time (time since heads in the aquifer have been reduced creating a gradient between the aquitards and adjacent aquifers) is approaching the time constant for the aquitards in question.

\section{Discussion}

Extensometer forensics involves using historical knowledge of the hydrogeological environment and the general historical anthropogenic impacts of the aquifer system along with available water-level and subsidence records that span the recording depth of the extensometer to help ascertain the viable hydromechanical properties of the system. By deconvolving the available water level and subsidence records into different pumping frequencies, a significant number of hydrologic parameters can be reasonably estimated even when the available record is limited and the long-term water levels may even be recovering. The biggest factor for maximizing the information gleaned from these records is the occurrence of cyclical pumping patterns at multiple frequencies from all compacting units being measured and the corresponding total subsidence record over the same time intervals. Figure 2 represents a 12-year snapshot of available water-level and compaction records at the Lorenzi extensometer site in Las Vegas Valley. The complex declining and recovering water level record and subsequent compaction record reveals much information about the nature and response of the aquifers and aquitards of this hydrologic system, but traditional means for estimating storage and hydraulic conductivity may not always be appropriate.

Extensometer data can be extremely valuable for helping to estimate or quantify aquifer and aquitard storage properties since storage is more sensitive to changes in deformation than to changes in hydraulic head (Burbey 2001). In spite of the fact that a single record of deformation spans multiple aquifers and aquitards, some important analytical and semi-analytical (and observational) methods have been applied that provide reasonable and realistic estimates of hydraulic conductivity and storage properties of the aquifer system at the Lorenzi site in Las Vegas when compared to the much more sophisticated but time consuming 1D numerical analysis developed by Pavelko (2004). The water-level and extensometer records shown in Figs. 2 and 3 reveal important aquifer characteristics that become helpful for understanding what generalizations can be made that help to constrain certain parametric aspects of the system.

This analysis outlines the importance of having cyclical water-level records (pumping and recovery) at multiple frequencies (in this case daily and seasonal) in all the aquifers that cover the extensometer recording depth interval in order 
Fig. 10 a Long-term deep piezometer record (blue) with trend line (orange), b seasonal water levels with trend removed and $\mathbf{c}$ seasonal water levels (blue) with fitted sine function (orange) revealing mean frequency and amplitude of water levels in the deep aquifer

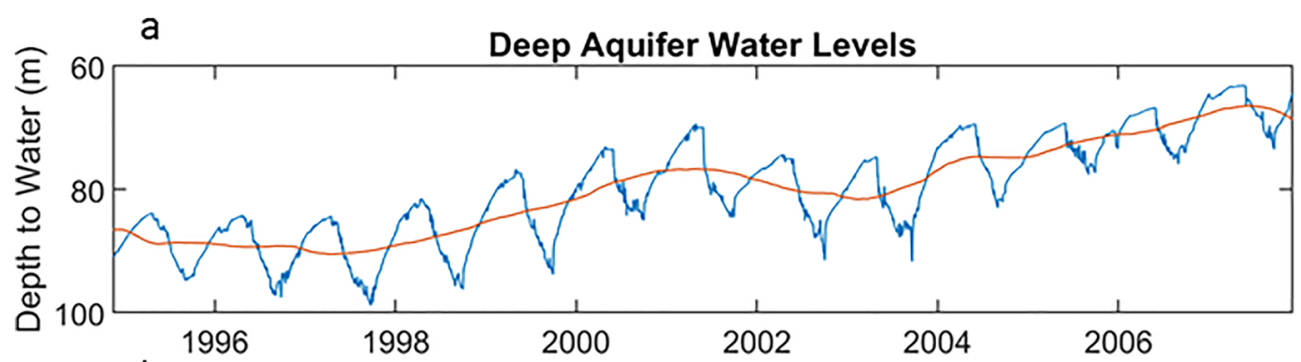

b

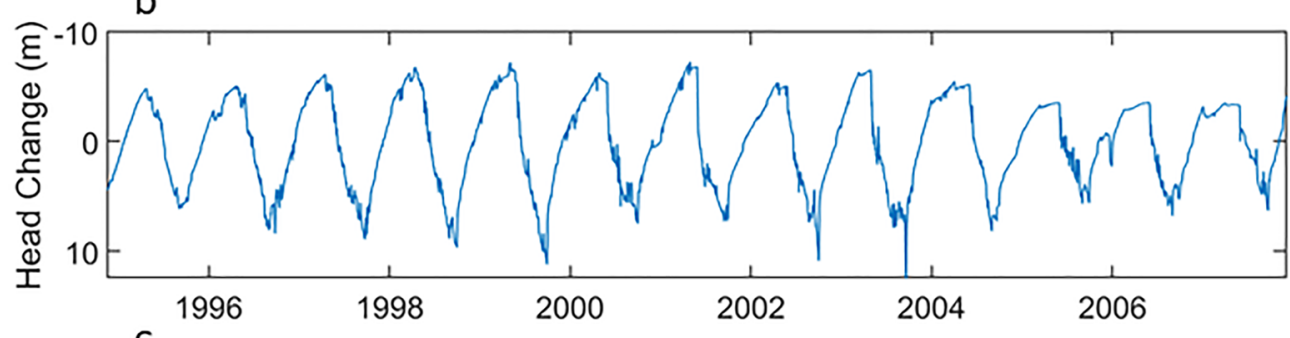

C

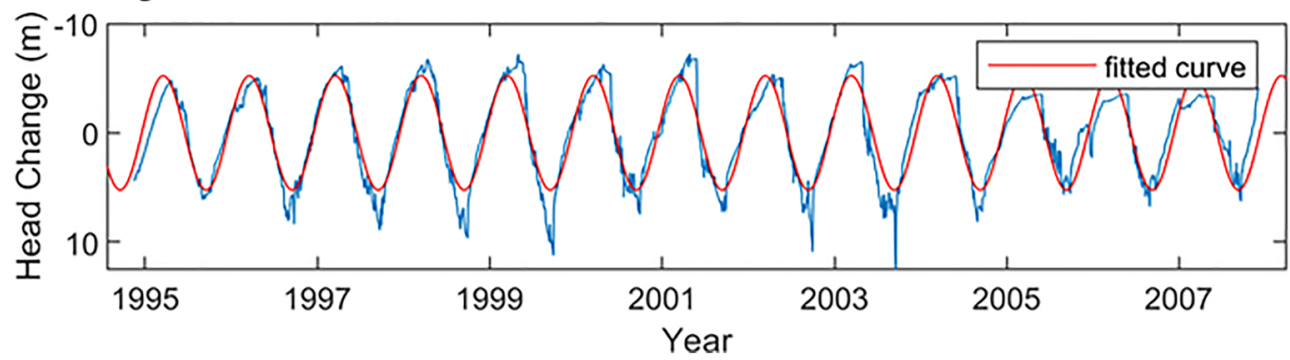

to adequately estimate hydraulic properties of the aquifers and aquitards. Without multilevel piezometers, it would not be feasible to provide more than a cursory overview of the system storage properties. Individual unit analysis (aquifers and aquitards) could not be achieved without water-level records from individual aquifers. Even with nested piezometer data, the assumption of constant aquitard parameters is required without having hydraulic head data at different depth intervals within each aquitard as the head distributions within these units can be quite complex when water levels decline and recover on an annual to decadal basis as is the case for the Lorenzi site (e.g. Fig. 12).

Results from the Theis pumping and recovery tests (Eqs. 1 and 2) for the 5-day selected period in July 1998, provide values of the aquifer horizontal hydraulic conductivity, which is not quantifiable using 1D subsidence modeling (Pavelko 2004). The large estimated hydraulic conductivity values for each of the three aquifers suggests that the gravel units in the aquifers are both areally extensive and dominate over the finer-grained lenses that may be present in the aquifers. The shape and amplitude of the head response is found to be highly sensitive to even small changes in hydraulic conductivity and assigned pumping. Hence, these parameters have a very narrow range of acceptable values. The shallow aquifer heads are the least diagnostic and this is at least partly attributed to the small overall amplitude in heads, the relative thinness of the aquifer, and the subsequent low rate of pumping from the aquifer. The middle and deeper aquifers have a much more defined and diagnostic cyclical drawdown and recovery pattern that can be inversely matched through iteratively modifying the storage and hydraulic conductivity of these aquifers. The result yields similar amplitudes and patterns of drawdown and recovery. The most notable difference is in the deep aquifer where the simulated heads trend toward a somewhat greater drawdown after 5 days of pumping and recovery compared to the actual head values. This difference may be attributed to heterogeneous conditions that are not accounted for, slight differences in overall pumping time, or the effective distance to the pumping wells. However, it is not expected that any of these factors would significantly affect the parameter estimates for storage and hydraulic conductivity (Table 2).

The analysis of seasonal cyclical pumping and recovery appears to be completely elastic as evidenced by the spectral analyses (Fig. 6) indicating that no lag exists between water level changes and changes in compaction. The Theis analysis allows for the differentiation of the amount of total compaction associated with the aquifers and individual aquitards. It is concluded that an average of $74 \%$ of the elastic compaction is attributed to the aquitards and $26 \%$ to the aquifers on an annual basis. The elastic contribution coming from the aquitards cannot be from the entire thickness of the aquitards as long as the heads within the aquitards have not reached equilibrium with the adjacent aquifers. Although the total amount of compaction that an aquitard ultimately can achieve 
Fig. 11 Plot of aquitard thicknesses responsible for contributing to elastic compaction associated with seasonal head changes for a range of elastic skeletal-specific storage values and hydraulic conductivity values of the aquitards. The orange box represents the range of parameter values found in the literature for extensometer sites in the United States. The red circle represents the optimal values from the numerical analysis of Pavelko (2004)

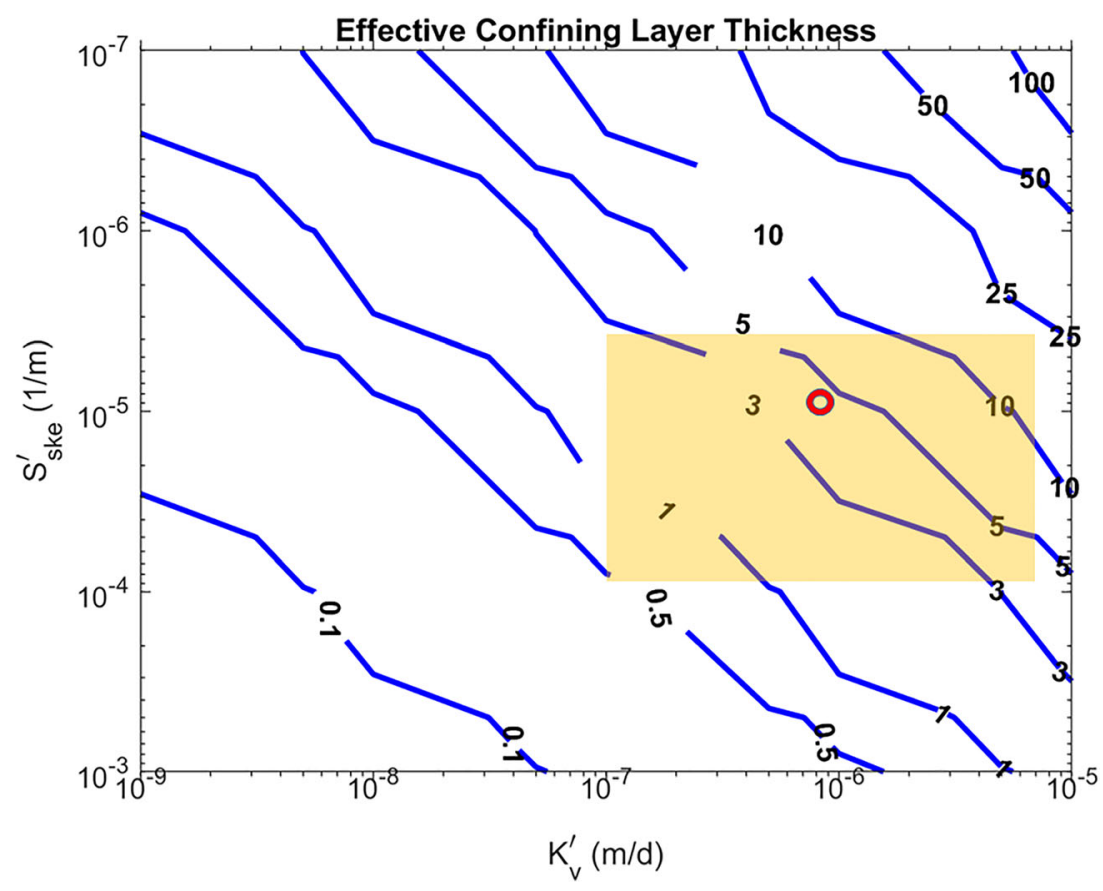

is independent of the amplitude of head change (Eq. 7), the thickness over which the elastic compaction is occurring for a period of time is completely dependent on the stress occurring within the aquitards over the pumping cycle. Furthermore, the thickness over which seasonal stress change occurs is dependent on the aquitard storage and hydraulic conductivity (Fig. 11). Based on Eq. (7), the thickness over which the seasonal elastic compression occurs is not a function of the amplitude of head change, but rather the time over which the stress is applied (182 days of pumping on an annual basis). The reasonable range of elastic skeletal-specific storage and aquitardvertical-hydraulic conductivity (vertical because these units drain vertically toward the aquifers) from previous hydrological investigations of Las Vegas Valley (Harrill 1976; Morgan and Dettinger 1996) brackets the range of possible aquitard thicknesses to a fairly narrow range. Affected aquitard thicknesses of 3-5-m span the middle of the likely range of hydraulic diffusivities $\left(K / S_{\mathrm{s}}\right)$ for the aquitards. Hence, the middle value of $4 \mathrm{~m}$ is chosen as the optimal elastic thickness based on Fig. 11, but the likely narrow band of thicknesses would not appreciably affect the outcome of the calculated aquitard parameter values (Table 3 ). Assuming homogeneous aquitard conditions means a total thickness of aquitard elastic compression is known along with the head change responsible for the compaction. Therefore, the skeletal elastic storage can be readily estimated and the approach outlined here produces the exact same value as the much more involved numerical modeling exercise described by Pavelko (2004).

In general, reasonable estimates of the inelastic skeletalspecific storage of compacting systems is difficult to accurately quantify. Part of the problem as already described is
Table 3 Calibrated and estimated hydraulic conductivity and storage parameters for the aquitards from this investigation and compared to the 1D MODFLOW results of Pavelko (2004) where the upper and lower reasonable values are provided along with the optimal value from his calibrated numerical model

\begin{tabular}{llll}
\hline Investigation & $\begin{array}{l}K_{\mathrm{v}}^{\prime} \mathrm{a} \\
(\mathrm{m} / \text { day })\end{array}$ & $\begin{array}{l}S_{\text {ske }} \\
(1 / \mathrm{m})\end{array}$ & $\begin{array}{l}S_{\text {ske }}^{\prime} \\
(1 / \mathrm{m})\end{array}$ \\
\hline This investigation (range) & $1.2 \times 10^{-6}$ & $2.5 \times 10^{-6}$ & $\begin{array}{l}S_{\text {skv }}^{\mathrm{b}} \\
(1 / \mathrm{m})\end{array}$ \\
& $1.4 \times 10^{-6}$ & $2.4 \times 10^{-5}$ & $1.6 \times 10^{-5}$ \\
& $5.4 \times 10^{-7}$ & - & $1.1 \times 10^{-5}$ \\
Pavelko (2004) upper/optimal/lower & $2 \times 10^{-3}$ & $7 \times 10^{-4}$ \\
& $9.1 \times 10^{-7}$ & $1 \times 10^{-7}$ & $1.6 \times 10^{-5}$ \\
& $6 \times 10^{-7}$ & $3 \times 10^{-7}$ & $3 \times 10^{-6}$ \\
\hline
\end{tabular}

${ }^{a}$ Represents upper, optimal, and lower calculated values associated with elastic aquitard thicknesses of 3, 4, and 5 m, respectively

${ }^{\mathrm{b}}$ Represents the upper and lower calculated values based on 90 (also optimal) and 200-year time constants for the aquitards, respectively 


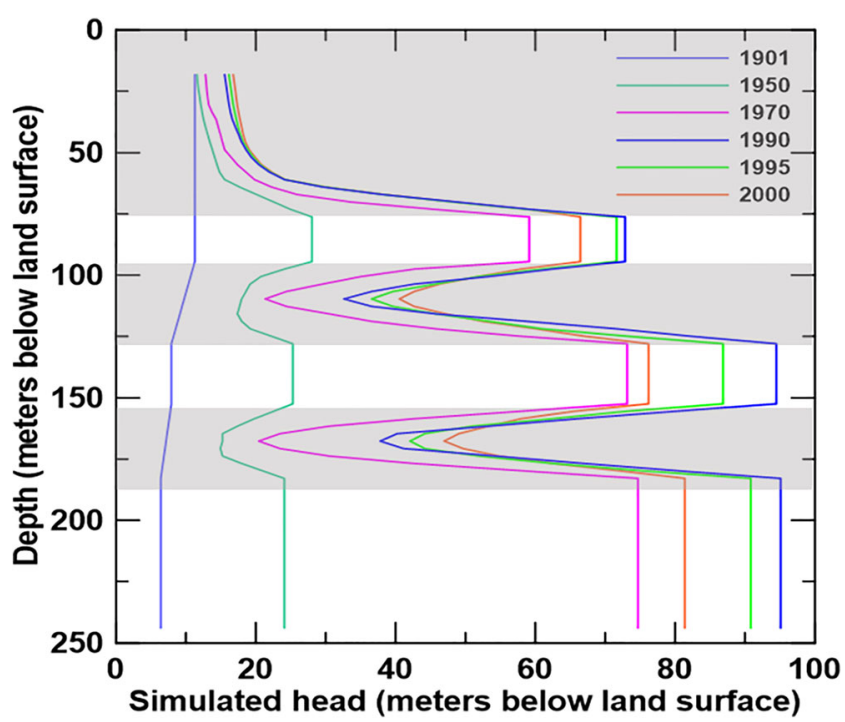

Fig. 12 Adaptation of Pavelko's (2004) transient simulated vertical head distribution through the three aquifers and aquitards for various times showing the complex nature of heads in the aquitards for both declining and recovering heads within the aquifers

that the aquitard heads are not in equilibrium nor do they reflect the heads of the measured concomitant aquifers (see Fig. 12). This is the result of the long time constants typically associated with these lower permeability units. Time constants can easily reach thousands of years for thick lowpermeability aquitards (Ireland et al. 1984; Riley 1998; Sneed and Galloway 2000). Another potential problem is that it typically requires knowing the historical pumping and subsidence from the onset of water-level declines in the basin, which can cover decades to even a century of time, extending to historical times where there are likely little to no measured data available. Consequently, inferences or extrapolations of these data often have to be made as was done by Pavelko (2004) in constructing his historical subsidence data for his simulation of the Lorenzi site. Further complicating matters occur when water levels are not continuing toward greater preconsolidation stress on an ongoing yearly basis. If water levels fluctuate and periods of annual recovery are occurring as is the case for the Lorenzi site (Fig. 2), typical stress-strain analysis methods developed by Riley (1969) for quantifying the inelastic skeletal-specific storage are also not reliable or appropriate.

In spite of these limitations, the general knowledge of historical pumping and drawdown within a basin can be used to make a reasonable estimate of the inelastic skeletal-specific storage even without a long observed record of the compaction history. Furthermore, this estimate can be made without foreknowledge of the maximum preconsolidation stress, which is required for modeling the time-dependent hydrodynamic lag and compaction history. In this analysis, a simplistic, but not unreasonable, approach is used and an aquitard time constant of 90 years is chosen, which is the cumulative time since the commencement of pumping and likely head declines within the principal aquifer system. This value clearly represents a minimum time constant, but is likely not far from the actual value as the total subsidence is asymptotically approaching equilibrium based on the cumulative subsidence values shown in Fig. 7a. Furthermore, based on historical ranges of aquitard hydraulic diffusivity (Epstein 1987; Hanson 1989; Pavelko 2004; Pope and Burbey 2004; Sneed and Galloway 2000) from modeling performed at
Fig. 13 Time constants (Eq. 7) for values of inelastic skeletalspecific storage and hydraulic conductivity of the aquitards. The orange-shaded region shows the range of time constants based on the analyses of this investigation and from other extensometer sites throughout the United States. The red circle represents Pavelko's (2004) optimal time constant from numerical analysis

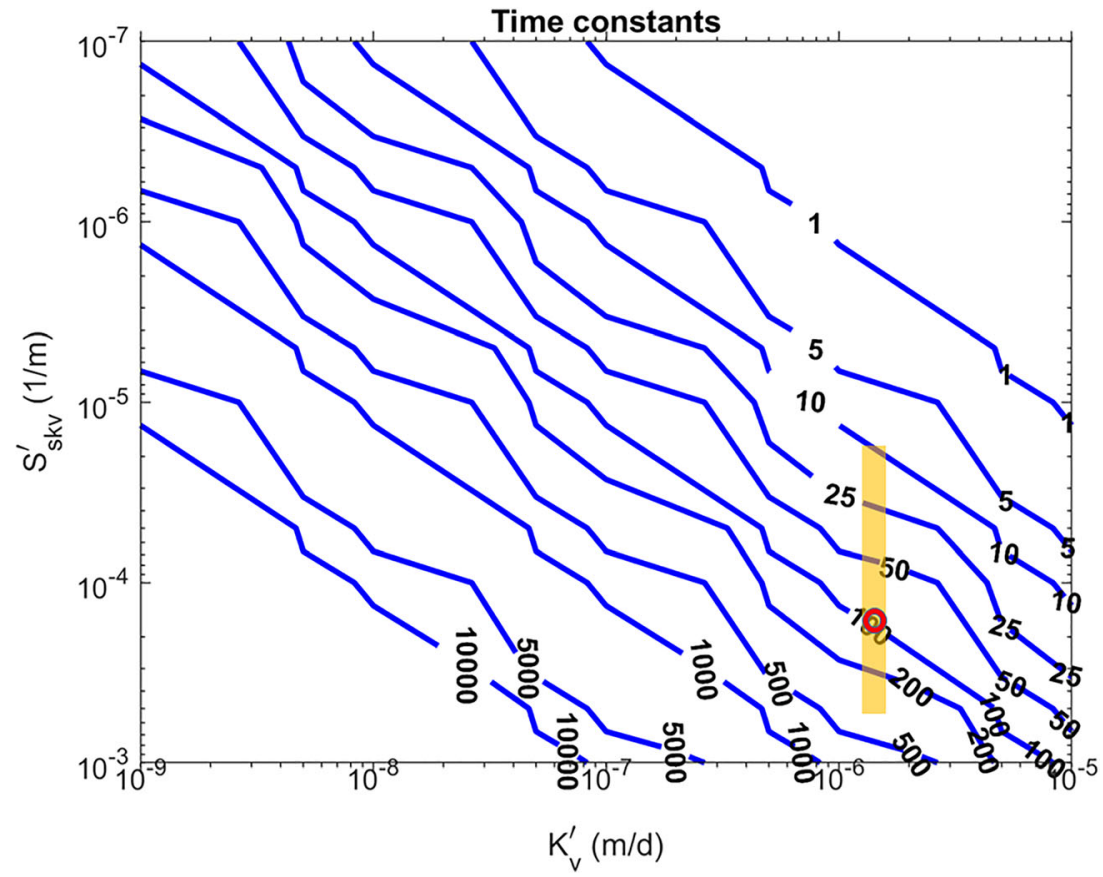


extensometer sites, the time constant range is most clearly attributed to aquitard thickness. Based on the average thickness of the middle and lower aquitards at the Lorenzi site, the range of time constants is typically in the 100-200-year range. Hence, the use of 90 years here is a low end value (see Fig. 13), but reasonable based on the outcome (Table 3 ) compared to the simulated values of Pavelko (2004), who estimated a 100 -year time constant for the aquitards. The semi-analytical approach here takes advantage of historical pumping, knowledge of the hydrostratigraphy, and understanding of the relationship between short and long-term head changes and aquifer compaction. These pieces of forensic evidence appear to provide a reasonable way to quantify the inelastic skeletalspecific storage in lieu of a more time consuming and rigorous numerical analysis.

\section{Conclusions}

The goal of this investigation was to determine if a simplistic semi-analytical approach could be used to reasonably quantify the aquifer and aquitard parameters at a point site (extensometer) in lieu of having to build a more complex and time-consuming numerical model to estimate parameter values. In virtually all cases in the literature some form of numerical model was developed to analyze the subsidence record obtained from extensometers to quantify the hydraulic conductivity and elastic and inelastic storage properties of the aquitards and the elastic storage of the aquifer units. These studies often involved reconstructing a complex history of pumping and interpolated or extrapolated subsidence and preconsolidation stress history before such data were physically collected.

With careful examination, extensometer data can provide more than just a continuous record of the total compaction history associated with the lowering of hydraulic heads within the measured zone of the extensometer pipe. This investigation reveals that important parameter values of the aquifer and aquitards including the hydraulic conductivities and elastic and inelastic specific storage can be reasonably quantified under the following conditions: (1) all hydrostratigraphic units important to the overall compaction record have been identified and their thicknesses established, (2) all the intervening aquifer hydraulic heads are measured over the length of the extensometer pipe, (3) cyclical pumping patterns are available for the length of the record and preferably at multiple frequencies, and (4) a reasonable historic understanding of the length of the pumping history affecting the measured record.

The results of this study suggest that through careful examination of the water level and compaction records, the different frequencies of pumping history can be isolated (deconvolved from the cumulative record) to quantify specific aquifer and aquitard properties. If pumping quantities and times are known at frequencies that portend an elastic response, the Theis equation can be used to develop the theoretical response to pumping and recovery and compared to the observed record whose shape and amplitude is a function of the rate of pumping and the hydraulic parameters of the aquifers. Once aquifer properties are characterized the aquitards can be evaluated provided these units are considered to be of the same composition (constant parameters) and homogeneous and isotropic in nature. A new technique was developed here using the expression for the time constant to identify the portion of the aquitards responsible for elastic deformation. Once identified, the compaction attributed to each aquitard and the elastic storage and hydraulic conductivity of the aquifer can be estimated. Finally, even if the period of record is limited and even if the annual water levels are not continually declining (increasing preconsolidation stress), the inelastic specific storage can be reasonably estimated through a general knowledge of the pumping history. The results of this investigation compare favorably with those developed through numerical modeling, suggesting that the more simplistic and less timeconsuming approach developed here is reasonable for estimating hydraulic parameters from a single extensometer record.

Acknowledgements The author would like to thank the US Geological Survey for providing all of the raw extensometer and piezometer data from the Lorenzi site in Las Vegas. The author also appreciates the critical and helpful comments by the two anonymous reviewers, which greatly improved the manuscript.

Open Access This article is distributed under the terms of the Creative Commons Attribution 4.0 International License (http:// creativecommons.org/licenses/by/4.0/), which permits unrestricted use, distribution, and reproduction in any medium, provided you give appropriate credit to the original author(s) and the source, provide a link to the Creative Commons license, and indicate if changes were made.

\section{References}

Abidin HZ, Andreas H, Gamal M, Wirakusumah AD, Darmawan D, Deguchi T, Maruyama Y (2008) Land subsidence characteristics of the Bandung Basin, Indonesia, as estimated from GPS and InSAR. J Appl Geodesy 2(3):163-167

Bell JW (1981) Subsidence in Las Vegas Valley. Nevada Bur Mines Geol Bull 95:84

Bell JW, Price JG (1991) Subsidence in Las Vegas Valley, 1980-91. Nevada Bureau of Mines and Geology Final Project Report 10, NBMG, Carson City, NV, 9 plates

Bell JW, Amelung F, Ramelli AR, Blewitt G (2002) Land subsidence in Las Vegas, Nevada, 1935-2000: New geodetic data show evolution, revised spatial patters, and reduced rates. Environ Eng Geosci 8(3): $155-174$

Blackman RB, Tukey JW (1958) The measurement of power spectra. Dover, New York

Burbey TJ (1995) Pumpage and water-level change in the principal aquifer of Las Vegas Valley, Nevada, 1980-90. US Geol Surv Water Resour Inform Rep 34:224

Burbey TJ (2001) Stress-strain analysis for aquifer-system characterization. Ground Water 39(1):128-136 
Burbey TJ, Warner SM, Blewitt G, Bell JW, Hill E (2006) Threedimensional deformation and strain induced by municipal pumping, part 1: analysis of field data. J Hydrol 319(1-4):123-142

Carruth RL, Pool DR, Anderson CE (2007) Land subsidence and aquifersystem compaction in the Tucso Active Management Area, southcentral Arizona, 1987-2005. US US Geol Surv Sci Invest Rep 20075190, $27 \mathrm{pp}$

Castellazzi P, Arroyo-Domínguez N, Martel R, Calderhead AI, Normand JCL, Gárfias J, Rivera A (2016) Land subsidence in major cities of central Mexico: interpreting InSAR-derived land subsidence mapping with hydrogeological data. Int J Appl Earth Obs Geoinf 47: 102-111

Epstein VJ (1987) Hydrologic and geologic factors affecting land subsidence near Eloy, Arizona. US Geological Survey, Tucson, AZ, 28 pp

Faunt CC, Sneed M, Traum J, Brandt JT (2016) Water availability and land subsidence in the Central Valley, California, USA. Hydrogeol J 24(3):675-684

Figueroa-Miranda S, Tuxpan-Vargas J, Ramos-Leal JA, HernándezMadrigal VM, Villaseñor-Reyes CI (2018) Land subsidence by groundwater over-exploitation from aquifers in tectonic valleys of central Mexico: a review. Eng Geol 246:91-106

Galloway D, Burbey TJ (2011) Review: Regional land subsidence accompanying groundwater extraction. Hydrogeol J 19:1459-1486

Galloway DL, Hoffman J (2007) The application of satellite differential SAR interferometry-derived ground displacements in hydrogeology. Hydrogeol J 15:133-154

Galloway D, Jones DR, Ingebritsen SE (eds) (1999) Land subsidence in the United States. US Geol Surv Circu 1182, 177 pp

Hanson RT (1989) Aquifer-system compaction, Tucson Basin and Avra Valley, Arizona. US Geol Surv Water Resour Invest Rep 88-4172, $69 \mathrm{pp}$

Harrill JR (1976) Pumping and ground-water storage depletion in Las Vegas Valley, Nevada, 1955-1974. NDWR, Carson City, Nevada, $70 \mathrm{pp}$

Helm DC (1975) One-dimensional simulation of aquifer system compaction near Pixley, California, 1: constant parameters. Water Resour Res 11(3):465-478

Helm DC (1976) One-dimensional simulation of aquifer system compaction near Pixley, California, 2: stress-dependent parameters. Water Resour Res 12(3):375-391

Heywood CE (2003) Summary of extensometric measurements in El Paso, Texas. US Geol Surv Water Resour Invest Rep 03-4158, 11 pp

Hoffmann J, Zebker HA, Galloway DL, Amelung F (2001) Seasonal subsidence and rebound in Las Vegas Valley, Nevada, observed by synthetic aperture radar interferometry. Water Resour Res 37(6): $1551-1566$

Hoffmann J, Galloway DL, Zebker HA (2003) Inverse modeling of interbed storage parameters using land subsidence observations, Antelope Valley, California. Water Resour Rese 39(2):SBH 5-1-513

Hsu W-C, Chang H-C, Chang K-T, Lin E-K, Liu J-K, Liou Y-A (2015) Observing land subsidence and revealing the factors that influence it using a multi-sensor approach in Yunlin County, Taiwan. Remote Sens 7(6):8202-8223

Hwang C, Yang Y, Kao R, Han J, Shum CK, Galloway DL, Sneed M, Hung W-C, Cheng Y-S, Li F (2016) Time-varying land subsidence detected by radar altimetry: California, Taiwan and North China. Sci Rep 6:28160

Ireland RL, Poland JF, Riley FS (1984) Land subsidence in the San Joaquin Valley, California, as of 1980. US Geol Surv Open-File Rep 82-370
Lieuallen-Dulam KK, Sawyer CS (1997) Implementing Intrawell, Intercell flow into finite-difference ground-water flow model. J Hydrol Eng 2(3): 109-112

Malmberg GT (1964) Land subsidence in Las Vegas Valley, Nevada, 1935-63. NDCR, Carson City, NV, 10 pp

Maxey GB, Jameson CH (1948) Geology and water resources of Las Vegas, Pahrump, and Indian Spring valleys, Clark and Nye counties, Nevada. Nevada State Engineer, Carson City, NV, 121 pp

Maxey GB, Jameson CH (1964) Land subsidence in Las Vegas Valley, Nevada, 1935-1963. Water Resources Information Series Report 5, Nevada Department of Conservation and Natural Resources, Carson City, NV, 10 pp

Minderhoud PSJ, Coumou L, Erban LE, Middelkoop H, Stouthamer E, Addink EA (2018) The relation between land use and subsidence in the Vietnamese Mekong delta. Sci Total Environ 634:715-726

Morgan DS, Dettinger MD (1996) Ground-water conditions in Las Vegas Valley, Clark County, Nevada. US Geol Surv Water Suppl Pap 2320-B, $124 \mathrm{pp}$

Pavelko MT (2000) Ground-water and aquifer-system-compaction data from the Lorenzi Site, Las Vegas, Nevada, 1994-1999. US Geol Surv 00-362

Pavelko MT (2004) Estimates of hydraulic properties from a onedimensional numerical model of vertical aquifer-system deformation, Lorenzi Site, Las Vegas, Nevada. US Geol Surv Water Resour Invest Rep 03-4083, 35 pp

Poland JF (1967) Land subsidence. US Geol Surv Prof Pap 575-A, pp $57-58$

Poland JF (1972) Subsidence and its control. In: Cook TD (ed) Underground waste management and environmental implications. AAPG Mem, Houston, TX, pp 50-71

Poland JF, Davis GH (1969) Land subsidence due to withdrawal of fluid. In: Varnes DJ, Kiersch G (eds) Reviews in engineering geology. Geological Society of America, Boulder, CO, pp 187-269

Pope JP, Burbey TJ (2004) Multiple-aquifer characterization from single borehole extensometer records. Ground Water 42(1):45-58

Riley FS (1969) Analysis of borehole extensometer data from central California. International Association of Hydrologic Sciences Publ. 89, IAHS, Wallingford, UK, pp 423-431

Riley FS (1998) Mechanics of aquifer systems: the scientific legacy of Joseph F. Poland. In: Borchers J (ed) Land subsidence: case studies and current research - proceedings of the Dr. Joseph F. Poland Symposium on Land Subsidence. Association of Engineering Geologists, Sacramento, CA, pp 13-27

Sneed M, Galloway D (2000) Aquifer-system compaction and land subsidence: measurements, analyses, and simulations - the Holly Site, Edwards Air Force Base, Antelope Valley, California. US Geological Survey, Sacramento, CA, 68 pp

Tosi L, Da Lio C, Strozzi T, Teatini P (2016) Combining L- and X-Band SAR interferometry to assess ground displacements in heterogeneous coastal environments: The Po River Delta and Venice Lagoon, Italy. Remote Sens 8(4):308

Zhang M, Burbey TJ (2016) Inverse modeling using PS-InSAR for improved land subsidence simulation in Las Vegas Valley, NV. Hydrol Process 30(24):4494-4516

Zhang Y, Wu J, Xue Y, Wang Z, Yao Y, Yan X, Wang H (2015) Land subsidence and uplift due to long-term groundwater extraction and artificial recharge in Shanghai, China. Hydrogeol J 23(8):18511866

Zhu L, Gong H, Li X, Wang R, Chen B, Dai Z, Teatini P (2015) Land subsidence due to groundwater withdrawal in the northern Beijing plain, China. Eng Geol 193:243-255

Zhuang C, Zhou Z, Illman WA (2017) A joint analytic method for estimating aquitard hydraulic parameters. Groundwater 55(4):565-576 